Shaker Jassem Gatan

A NEW DESIGN OF M.V - VACUUM CIRCUIT BREAKER - WITH AUXILIARY UNITS DAMPING TECHNIQUES FOR SOFT INTERRUPTER APPLICATIONS

Summary of the Doctoral Thesis

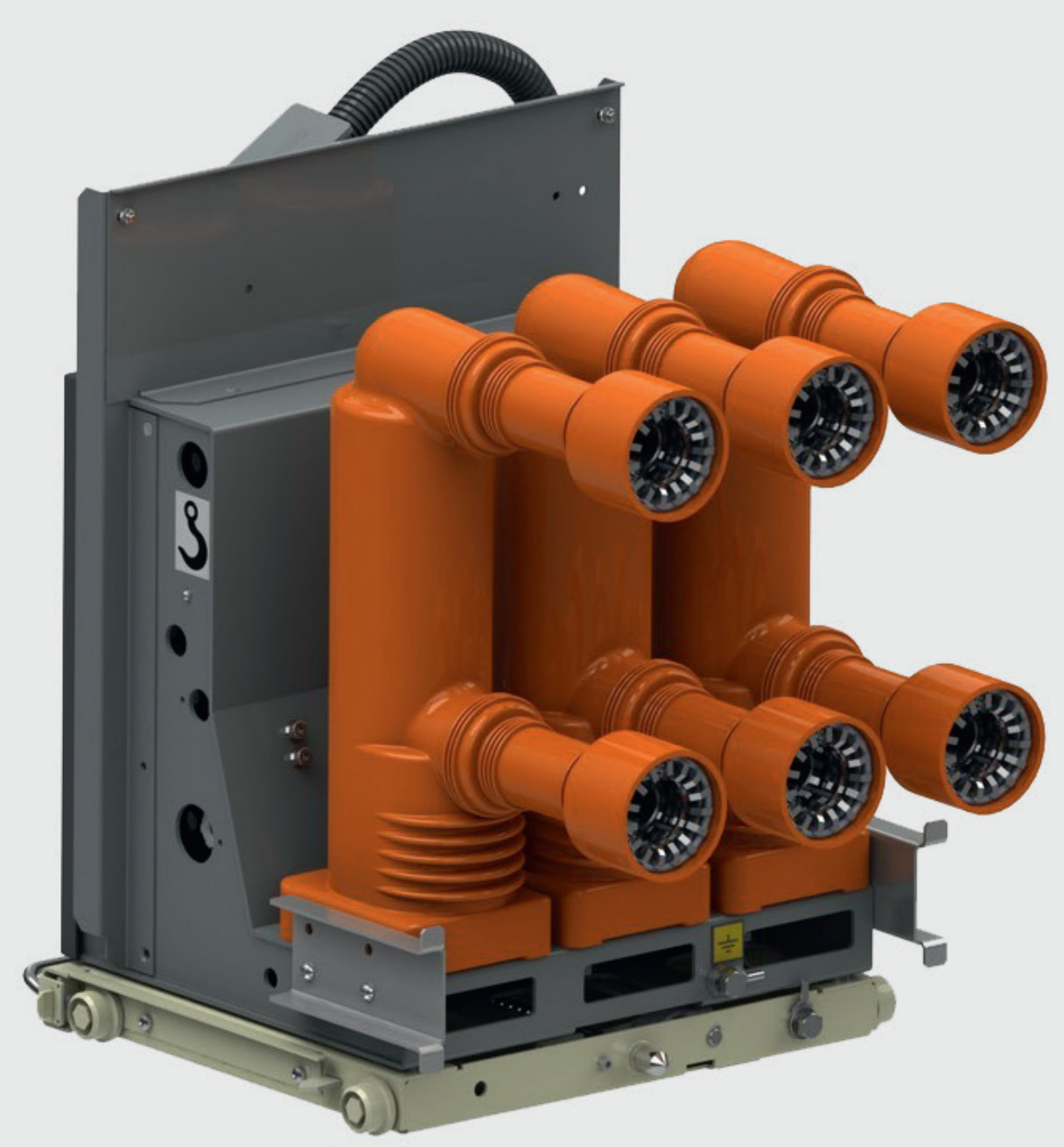


RIGA TECHNICAL UNIVERSITY

Faculty of Power and Electrical Engineering Institute of Power Engineering

SHAKER JASSEM GATAN

Doctoral Student of the Study Program

"Power and Electrical Engineering"

\section{A NEW DESIGN OF M.V - VACUUM CIRCUIT BREAKER - WITH AUXILIARY UNITS DAMPING TECHNIQUES FOR SOFT INTERRUPTER APPLICATIONS}

Summary of the Doctoral Thesis

Scientific supervisor Associate Professor Dr. sc. ing. ANDREJS PODGORNOVS

Riga 2019 
Gatan, S. J. A New Design of M.V - Vacuum Circuit Breaker - With Auxiliary Units Damping Techniques for Soft Interrupter Applications. Summary of the Doctoral Thesis. Riga: RTU Press, 2019. 35 p.

Published in accordance with the decision of the Promotion Council "RTU P-14" of 28 May 2019, Minutes No. 69.

Cover photo from "Eltechnika" JSC.

ISBN 978-9934-22-407-2 (print)

ISBN 978-9934-22-408-9 (pdf) 


\section{DOCTORAL THESIS PROPOSED TO RIGA TECHNICAL UNIVERSITY FOR THE PROMOTION TO THE SCIENTIFIC DEGREE OF DOCTOR OF ENGINEERING SCIENCES}

To be granted the scientific degree of Doctor of Engineering Sciences, the present Doctoral Thesis has been submitted for the defence at the open meeting of RTU Promotion Council on December 9, 201914.00 at the Faculty of Power and Electrical Engineering of Riga Technical University, 12 k-1 Azenes Street, Room 212.

\section{OFFICIAL REVIEWERS}

Lead Researcher Dr. habil. sc. ing. Vladislavs Pugačevs

Latvian Academy of Sciences, Institute of Physical Energy, Latvia

Lead Researcher Dr. sc. ing. Svetlana Orlova

Latvian Academy of Sciences, Institute of Physical Energy, Latvia

Researcher Dr. sc. ing. Victor Astapov

Tallinn University of Technology, Estonia

\section{DECLARATION OF ACADEMIC INTEGRITY}

I hereby declare that the Doctoral Thesis submitted for the review to Riga Technical University for the promotion to the scientific degree of Doctor of Engineering Sciences is my own. I confirm that this Doctoral Thesis had not been submitted to any other university for the promotion to a scientific degree.

Shaker Jassem Gatan (signature)

Date:

The Doctoral Thesis has been written in English. It contains 3 chapters; conclusions; 79 figures; 5 tables; 4 appendices; the total number of pages is 105. The Bibliography contains 118 titles. 


\section{CONTENTS}

GENERAL DESCRIPTION OF THE WORK ............................................... 5

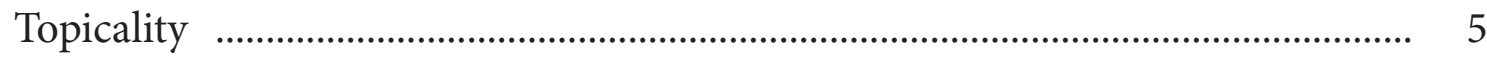

Technical engineering specification ................................................................. 5

Object of the Research ........................................................................................... 6

Aim and Tasks of Research ........................................................................... 6

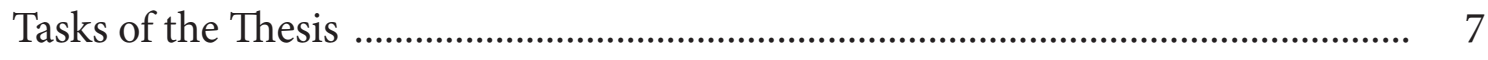

Applied Research Methods .................................................................................. 8

Scientific Novelty of Research ............................................................................... 8

Scientific and Practical Approbation of the Work ................................................. 9

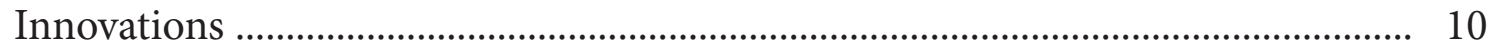

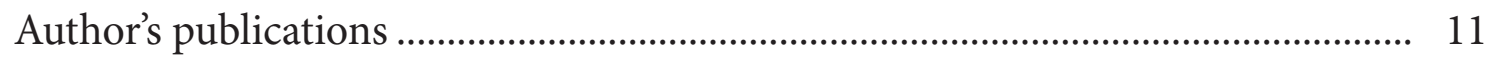

STRUCTURE OF THE WORK …........................................................... 13

1. Medium Voltage Switching Parameters .......................................................... 13

2. Contacting Materials of M.V Switching …...................................................... 13

3. Design Circuit \& Mathematical Applications .............................................. 13

DISSERTATION BRIEFLY …................................................................. 14

I. FABRICATING AND DESIGNING ................................................. 16

1. HYPOTHESIS OF STATIC VACUUM INTERRUPTER ........................ 16

1.1. Designing, fabricating and modifying of the Petersen Reactor

Coils Automatic Tuning …............................................................................ 17

1.1.1. Fabricating anode \& cathode coils ............................................. 17

1.1.2. Mathematical Designing of Petersen Coils ............................... 20

1.2. Inserting of LTT Rectifying Thyristor Setting Circuit ............................. 24

1.3. Optimization of Mathematical Application

for Damping Technique .................................................................... 24

1.3.1. Basic Module of Inductive Reactance Circuit ............................ 24

1.4. Synthesis of Mathematical Model .......................................................... 25

1.5. Synthesis of MATLAB/Simulink Models ................................................ 26

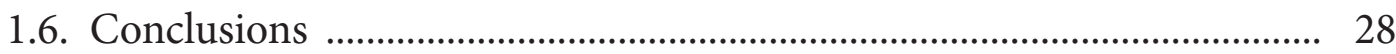

II. MATHEMATICAL PARAMETERS ......................................................... 29

2.1. Experiment Test for Calculating of Oscillating - Chopping

Currents - Proving Method

2.2. Experiment Prototype for Magnetic Field Behavior -

Fabricated Process

MAIN CONCLUSIONS …......................................................................... 32

BIBLIOGRAPHY ............................................................................ 33 


\section{GENERAL DESCRIPTION OF THE WORK}

\section{Topicality}

The main object of this research is a plan for designing and constructing of a new circuit breaker for medium voltage switching interrupter. In order to obtain soft interrupter, the following incidents are always happening inside the switching process: arcing currents, chopping currents and transient over voltages.

Beginning from the $18^{\text {th }}$ century, all circuit breakers were filled with oil to prevent arcing currents, chopping currents and transient over voltages, which decomposed the dielectric material properties. In the beginning of the $20^{\text {th }}$ century, all companies replaced the oily CBs by using new SF- 6 Sulfur hexafluoride, non-flammable gas, to prevent explosion inside interrupter, but the success is still limited.

\section{Technical engineering specification}

Although most scholars, scientists and researching manufacturing companies are still confined in their efforts by using only a sustainable material such as copperchrome alloys "Metallurgy Vacuum Circuit Breaker" for protection against ionization and arcing currents, which are generated inside vacuum interrupter itself. However, the severe arcing currents, high scales of chopping currents may cause "accidental explosions" and are still registered in many factories and power generation plants.

In addition, static switching prototype creation still has many obstacles for a number of reasons: the automatic system is weakly developed, there are a lot of difficulties with the financial issue, because even the process of developing mathematical methods is difficult due to the many assumptions. The author of the Doctoral Thesis proposes a new technical solution by making a Petersen reactor coil for automatic adjustment - two coils with LTT thyristor set insertion in medium voltage switchgear [1]-[23] using MATLAB/ Simulink. 


\section{Object of the Research}

The object of research of the Thesis is the arc current and the chopping current occurring inside the vacuum interrupter. The aim of the Thesis is to use additional Petersen reactor coils for automatic adjustment of the switching process, as well as optimization of LTT thyristor set implementation for suppressing arc currents and chopping currents. In addition, the solution of the mathematical model synthesis problem obtains the result of static process modeling as a softswitching circuit breaker of a vacuum interrupter. Although there are three negative phenomena, mainly inside vacuum interrupter could be disruptive the insulation levels in medium voltage apparatus. However, there are also other disruptive phenomena, which are not so dangerous.

1. Restrikes of voltages - fast oscillating voltages.

2. Prestrikes over voltages - fast oscillating currents.

3. Multiple re ignitions.

4. Voltage escalation - oscillations phenomena.

5. Post-arc currents.

6. Thermal - Joule heating.

The author of the Thesis proposes a new invention, a softswitching circuit breaker, which completely eliminates arc current, chopping current and transient overvoltage.

\section{Aim and Tasks of Research}

The aim of my scientific work is to develop a methodology for creating the soft starting vacuum interrupter in medium voltage.

The author of the Thesis developed and adapted Petersen Reactor Coil Automatic Tuning for treatment of arcing currents "main obstacle", including treatment of chopping currents and transient over voltages for second steps. Thus, the soft interrupter needs a new modification steps by optimization of mathematical Laplace formula and by creating a power electronics rectifying process for damping technique for automatic tuning.

For this purpose, one scholar created one sample "Harris model".

Summarizing of Harris model switching interrupter was $600 \mu \mathrm{s}$ [1], [3], [5]. 
Table 1

Three MATLAB/Simulink/Design Samples Were Verified

\begin{tabular}{|c|c|c|}
\hline Sample one & $\begin{array}{c}\text { SION } \\
\text { 3AES } \\
\text { SIMENINES }\end{array}$ & $\begin{array}{l}63 \mathrm{~A} \text { arcing current / } 3 \mathrm{~A} \text { chopping current } \\
\text { for } 12 \mathrm{kV}\end{array}$ \\
\hline Sample two & $\begin{array}{c}\text { SION } \\
\text { 3AES } \\
\text { SIMENINES }\end{array}$ & $\begin{array}{l}125 \mathrm{~A} \text { arcing current / } 5 \mathrm{~A} \text { chopping current } \\
\text { for } 12 \mathrm{kV}\end{array}$ \\
\hline Sample three & $\begin{array}{c}\text { SION } \\
\text { 3AE1 } \\
\text { SIMENINES }\end{array}$ & $\begin{array}{l}250 \mathrm{~A} \text { arcing current / } 7 \mathrm{~A} \text { chopping current } \\
\text { for } 12 \mathrm{kV}\end{array}$ \\
\hline
\end{tabular}

\section{Tasks of the Thesis}

1. To overview several research manuscripts on designing of damping applications that can be used in author's investigation for possibility of damping arcing currents (diffuse \& constricted modes).

2. To develop the function of Petersen Rector Coil Automatic Tuning, to design Anode Coil and Cathode Coil by applying the mathematical designing theory of designing Petersen application.

3. To develop recommendations for the Axel magnetic field utilization based on a prototype described in an international research paper data.

4. To carry out modeling experiments using synthesizing calculating method, in order to develop a calculation method to define the maximum values of chopping currents and to compare with the experiments (3 A / 5 A / 7 A) ABB carried out in Norway.

5. To define the objective function, to synthesize the necessary mathematical model/formula that will be used in optimization and inserting of LTT Thyristor set.

6. To optimize of the damping application method using MATLAB/Simulink software. 


\section{Applied Research Methods}

The following research methods and means are used in this Thesis:

- qualitative research;

- qualitative research on mathematical analysis for integration of power electronics in MV switching process with new LTT technique;

- new application of mathematical damping optimization technique;

- optimization of snubber circuit theory in MV application technique;

- analysis of commutation process of di/dt in medium voltage switching;

- damping of oscillating switching - MATLAB/Simulink experiment tests.

\section{Scientific Novelty of Research}

The used methods and the research allowed to achieve the following:

1. Two reactor coils (Anode Coil and Cathode Coil) were designed by developing the existing Peterson Reactor Coil Automatic Tuning in real time for the purpose of damping of arcing currents, chopping currents and transient over voltages to be the soft interrupter.

2. The steps of designing stages were done optimizing the mathematical application (synthesis of mathematical model) by inserting of LTT.

3. The results of the damping application used by Laplace transformation theory were presented in models in MATLAB.

4. The results that vacuum interrupter be able for working in the transition rate $\mathrm{d} i / \mathrm{d} t$ by a snubber power electronics process for shifting of the arcing currents and chopping currents precisely.

5. The MATLAB Invention is that the switching interrupter works as the sequential processing steps in uniform formula ( $200 \mu$ s to $800 \mu \mathrm{s}$ ) between the electroplates.

6. The research proved that the snubber circuit in power electronics such as LTT thyristor type could be used. 
7. The basic background steps of my research are based on doctoral theses by Mitchell, G. R and Harris, L. P. I made my research for quenching of arcing currents due to switching process inside vacuum interrupter itself.

\section{Scientific and Practical Approbation of the Work}

The research and its scientific novelty are scientifically approved in publications, conference proceedings and also practically approbated based on: Scientific Research Institute of Electrophysical Apparatus-Saint Petersburg whose constructed one sample reactor coil with thyristors auxiliary sets for charging and discharging application;

The Behlke Power Electronics LCC in Germany also constructed a one unit of LTT as Crowbar -snubber application (Behlke HTS 800$100-\mathrm{SCR})(11 \mathrm{kV} / 150 \mathrm{kA}$ ) for parallel operating process, which is commercially available internationally and ABB (USA) research data

The research results have been presented in the following international conferences:

1. "Theoretical proved for synchronizing switching times of vacuum Interrupter with power electronics - Thyristor for the same transition rates between electroplates and thyristor for medium voltage switching system". Third International conference on artificial intelligence Lodz university of technology; Lodz-Poland, September 2016.

2. "Analysis of parameters and time sequences for full operation mode of vacuum Interrupter for medium voltage switching system". 52 ${ }^{\text {nd }}$ International scientific conference on information, communication and energy system (ICEST 2017) Niš, Serbia, June 28-30, 2017.

3. "Analysis of parameters of transient over-voltages and measuring of chopping currents on vacuum Interrupters associated with medium voltage switching system". $52^{\text {nd }}$ International scientific conference on information, communication and energy system (ICEST 2017) Niš, Serbia, June 28-30, 2017. 


\section{Innovations}

For some of the research results the following patents have been registered:

1. Flexibility of transition materials $\mathrm{d} i / \mathrm{d} t \& \mathrm{~d} u / \mathrm{d} t$ criteria, a mathematical model was constructed by two scientists Glinkowski and Greenwood proved of the switching electroplates $(50 \mathrm{~A} / \mu \mathrm{s}<\mathrm{d} i / \mathrm{d} t<1250 \mathrm{~A} / \mu \mathrm{s})$ that was supporting author researching for studying a parallel operation mode, between electroplates and semiconductor materials, $11 \mathrm{kV}$ In MATALB/Simulink experiment tests.

The main purpose for proved of manuscript that enhanced the using of crowbar application, basically for the process of Peterson Reactor Coil (0093-9994/03\$17.00@2003IEEE).

2. The mathematical formula of Harris model enables author fabricating the existing of Peterson coil automatic tuning in real time $600 \mu \mathrm{s}$ of Inductive reactance $\omega L$ value of $11 \mathrm{kV}$ at rate of $I_{c}=250 \mathrm{~A}$ in damping application techniques for oscillating chopping currents and transient over voltages in vacuum interrupter by using of Laplace theory including implementing by MATLAB.

3. These data sheet was assumed the maximum arcing current $(12 \mathrm{kV} / 250 \mathrm{~A})$ for my designing novelty and author researching proved at three values of chopping current $(3 \mathrm{~A} /$ $5 \mathrm{~A} / 7 \mathrm{~A})$.

4. IEEE tutorial on the vacuum switchgear " TP-135-0" confirmed that "when the current chopped inside vacuum, its causes the changing in the frequency values $50 \mathrm{~Hz}$ to $150 \mathrm{~Hz}$ and $400 \mathrm{~Hz}$ " this phenomenon invited me to study the mathematical behaviors. Author interpretation is that "there is an interval in phenomena among arcing current, chopping current and transient over voltages come together to generate switching impulses in primitive mode inside interrupter" this patent according to the Fourier series phenomena in more detail is explained by Erwin Kreyszig the Advanced Engineering Mathematics \& MATLAB /Simulink application. 


\section{Author's publications}

Researches carried out in this dissertation have been presented in the following publications:

1. "The Modern Methods for Designing of Medium Voltage Switchboards Technology of Power Plant's Refineries," Proceedings of the IEEE $3^{\text {rd }}$ workshop on advances in information, Electronic and Electrical Engineering (AIEEE), Riga Technical University, Riga, Latvia, 2015. ISSN 978-1-5090-1201-5.

https://doi.org/10.1109/aieee.2015.7367284.

2. "Synchronizing Switching Times of Vacuum Interrupters for Medium Voltage - Switchboards' Techniques," Proceedings of the IEEE $3^{\text {rd }}$ International conference on artificial intelligence (AIPR 2016), University of Technology - Lodz, Poland Lodz, 2016. ISBN 978-1-4673-9187-0.

https://doi.org/10.1109/icaipr.2016.7585204.

3. "Algorithmic Application for Calculation of chopping Currents and High Transient over-voltages for a New Vacuum Interrupter," 2017 International Scientific Conference on Information, Communication and Energy Systems and Technologies (ICEST 2017), University of Nis Serbia. ISSN 2603-3259.

4. "Analyzing Parameters of Load Flows and Characteristics of Medium Voltage Switching System - Refinery Power Plant," 2017 International Scientific Conference on Information, Communication and Energy Systems and Technologies (ICEST 2017), University of Nis Serbia. ISSN 2603-3259.

5. "A New Method for Parallel Operation Units by Synchronized Instrument Transformers -Associated with Switchboards P1," 2017 International Scientific Conference on Information, Communication and Energy Systems and Technologies (ICEST 2017), University of Nis Serbia, 2017. ISSN 2603-3259.

6. "A New Method for Parallel Operation Instrument Transformers Units by - Associated with Switchboards," 2017 IEEE 58th International Scientific Conference on Power and Electrical Engineering of Riga Technical University (RTUCON), Okct. 2017. https://doi.org/10.1109/rtucon.2017.8125623. 
7. "Analysis of Parameters and Time Sequences for Full Operation Mode of Vacuum Interrupter for Medium Voltage Power Plants," American Journal of Information Science and Technology, vol. 2, no. 2, 2018, pp. 57-63. https://doi.org/10.11648/j.ajist.20180202.15. 


\section{STRUCTURE OF THE WORK}

\section{Medium Voltage Switching Parameters}

1.1 Switching parameters

1.2 Switching characteristics and multiple voltage escalation

1.3 Capacitive current Interrupter

1.4 Inductive current Interrupter

1.5 Experiment test one - Transition Rate of di/dt

1.6 Experiment test two - Formation of Radial Magnetic Field

1.7 Conclusions

\section{Contacting Materials of M.V Switching}

2.1 Analysis of technical materials inside vacuum interrupter

2.2 Types of vacuum arcs

2.3 Calculating of Joule heating in vacuum interrupter

2.4 Synthesis of mathematical model

2.5 Electrode effects and break- down

2.6 Transient over voltages formula

2.7 Mathematical Fourier transformation model

2.8 Experiment test for calculating of chopping currents

2.9 Calculating of NSD discharging times - Experiment Test

2.10 onclusions

\section{Design Circuit \& Mathematical Applications}

1.1 Hypothesis of static vacuum Interrupter

3.1.1 Analysis of the designing of the existing Petersen Coil Automatic Tuning

3.1.2 Fabricating of Petersen Coil -Anode Coil \& Cathode Coil

3.1.3 Inserting of LTT rectifying Circuit

3.1.4 Synthesis of mathematical model

3.1.5 Synthesis of MATLAB/Simulink models

Main conclusions

Appendices

Appendix 1 - Damping Mathematical Application -Example

Appendix 2 - Splitting of Arcing Currents - Power Electronics -

Experiment Tests

Appendix 3 - Pulse Power Equipment by LTT Thyristor

Appendix $4-$ Transition of Switching Rates $\mathrm{d} u / \mathrm{d} t \& \mathrm{~d} i / \mathrm{d} t$ on Snubber Application 


\section{DISSERTATION BRIEFLY}

In order to get better understanding of my research term specifically. It depends on the existing of the industrial manuscripts, which involve medium voltage interrupter process as a standard, even if that was publishing dates because the valuable samples were really reflected in scientific information. So, we shall confine our attention mainly on only the above three measurements: arcing currents, chopping currents and transient over voltages.

G.R. Mitchell classified two types of arcing currents:

1. Diffuse Mode.

2. Constricted Mode.

In addition, there are two elements that could be made a disruptive of the dielectric insulation levels; chopping currents and transient over voltages.

My investigation confirmed that there is an intervene between chopping currents events and transient over voltages when they come together and initiate a high escalation of switching impulses in a primitive mode (first invention step).

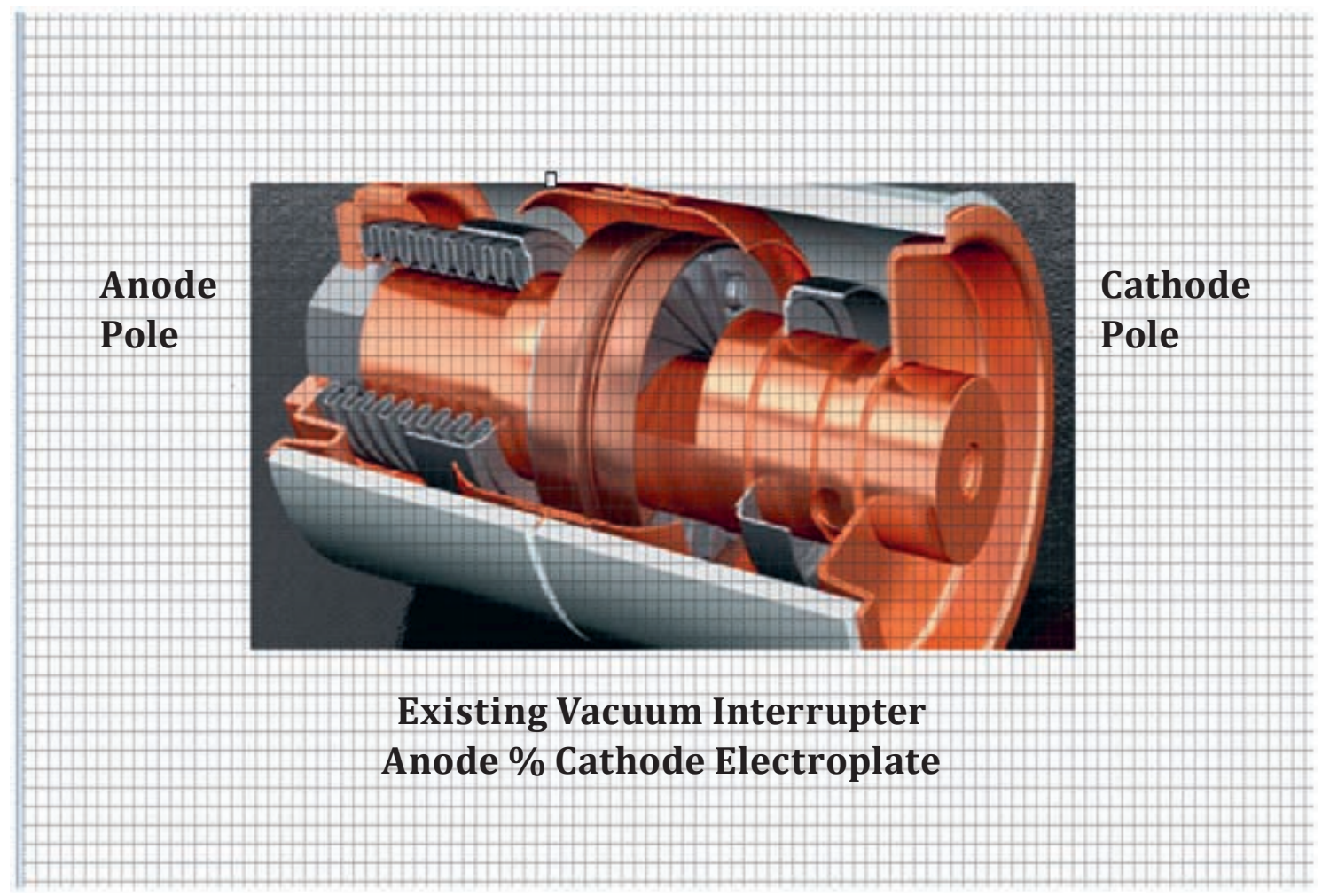

Fig. 1.1. The existing vacuum interrupter under investigation. 

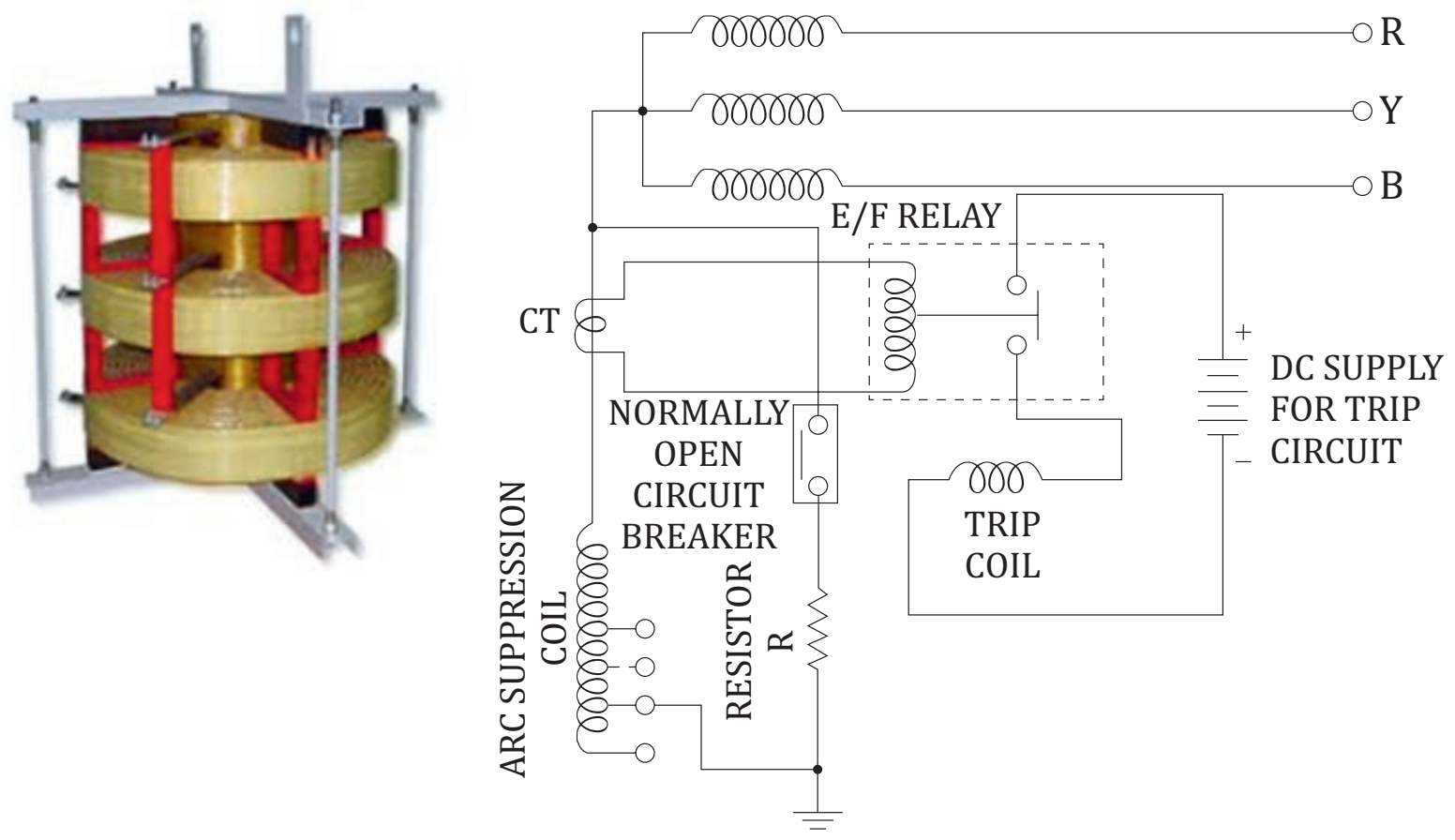

Fig. 1.2. Petersen reactor coils automatic tuning under research.

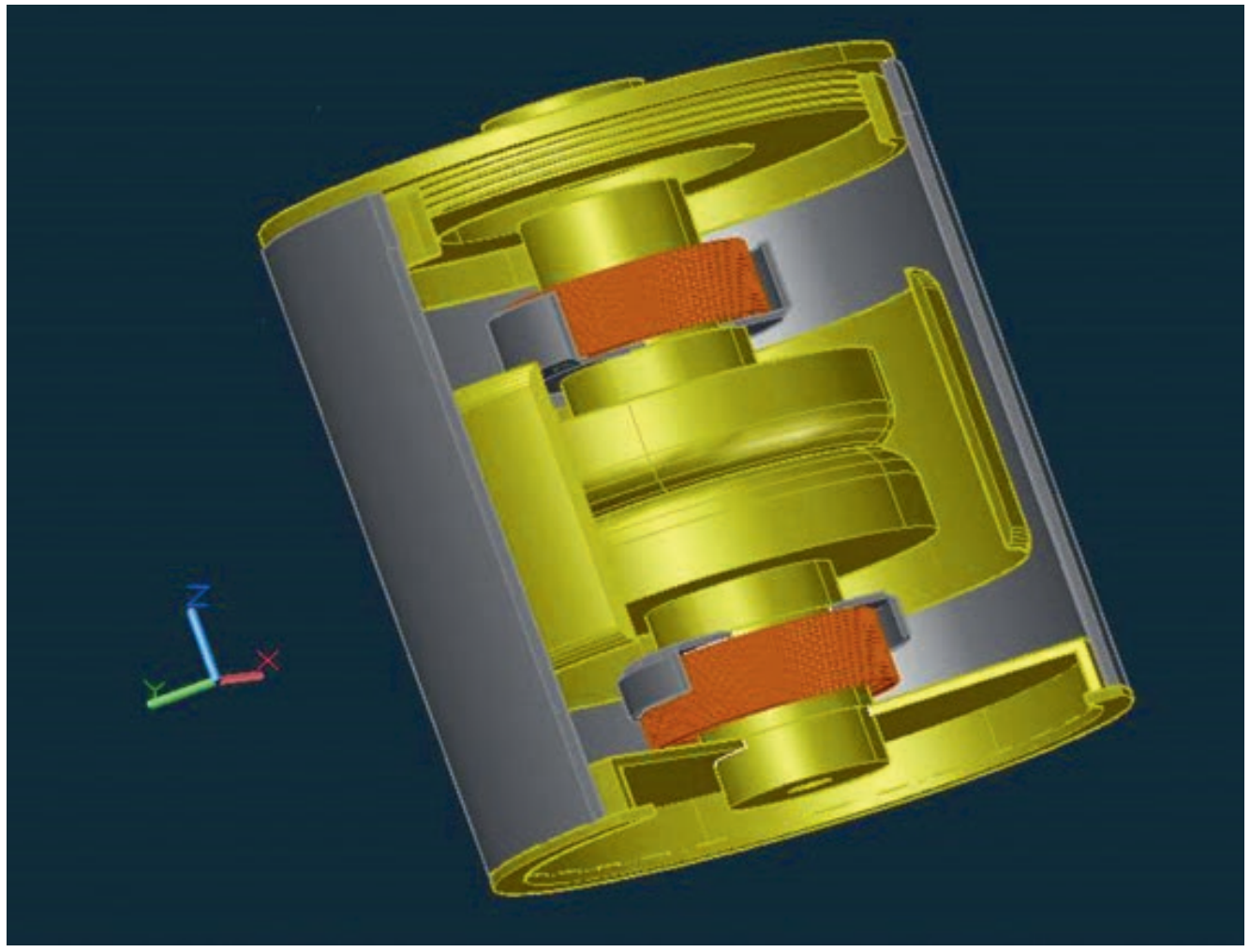

Fig. 1.3. Fabricated Petersen coils - anode and cathode poles. Sample 1. 


\section{FABRICATING AND DESIGNING}

\section{HYPOTHESIS OF STATIC VACUUM INTERRUPTER}

My Thesis proposed that created damping processes unit for occurrence of the soft starting interrupter has the following steps:

1. Hypothesis of static vacuum interrupter.

1.1 Designing, fabricating and modifying of the Petersen Reactor Coils Automatic Tuning.

1.1.1 Fabricating Anode \& Cathode Coils.

1.1.2 Mathematical designing of Petersen coils.

1.2 Inserting of LTT rectifying thyristor setting circuit.

1.3 Optimization of mathematical application for damping technique.

1.4 Synthesis of mathematical model.

1.5 Synthesis of MATLAB/Simulink models.

1.6 Conclusions.

2. Experiment test and samples.

2.1 Experiment test for calculating of oscillating-chopping currents.

2.2 Experiment prototype for magnetic field behavior.

2.3 Fast-discharging unit - prototype - Russian Institute. Main conclusions.

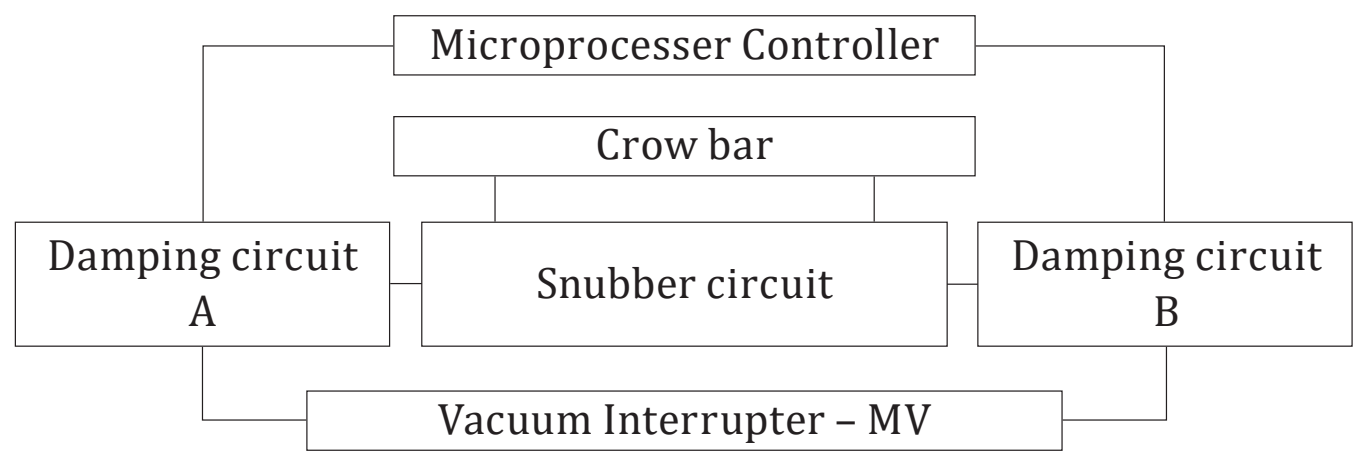

Fig. 1.4. Single Line diagram of vacuum interrupter under investigation (novelty). 


\subsection{Designing, Fabricating and Modifying of the Petersen Reactor Coils Automatic Tuning}

Petersen coils are used in faults of 3-phase systems to limit arcing currents during earth faults process. The coil was first developed by William Petersen and still installed in all substations. However, the use of modern power electronics has revolutionized the performance of these classical solutions called Arc Suppression Coil (ASC) and the modern power electronics have been offered a new automatic tuning technique. My second invention was fabricated in order for this reactor to be more convenient in each pole of interrupter [1], [7], [18].

\subsubsection{Fabricating Anode \& Cathode Coils}

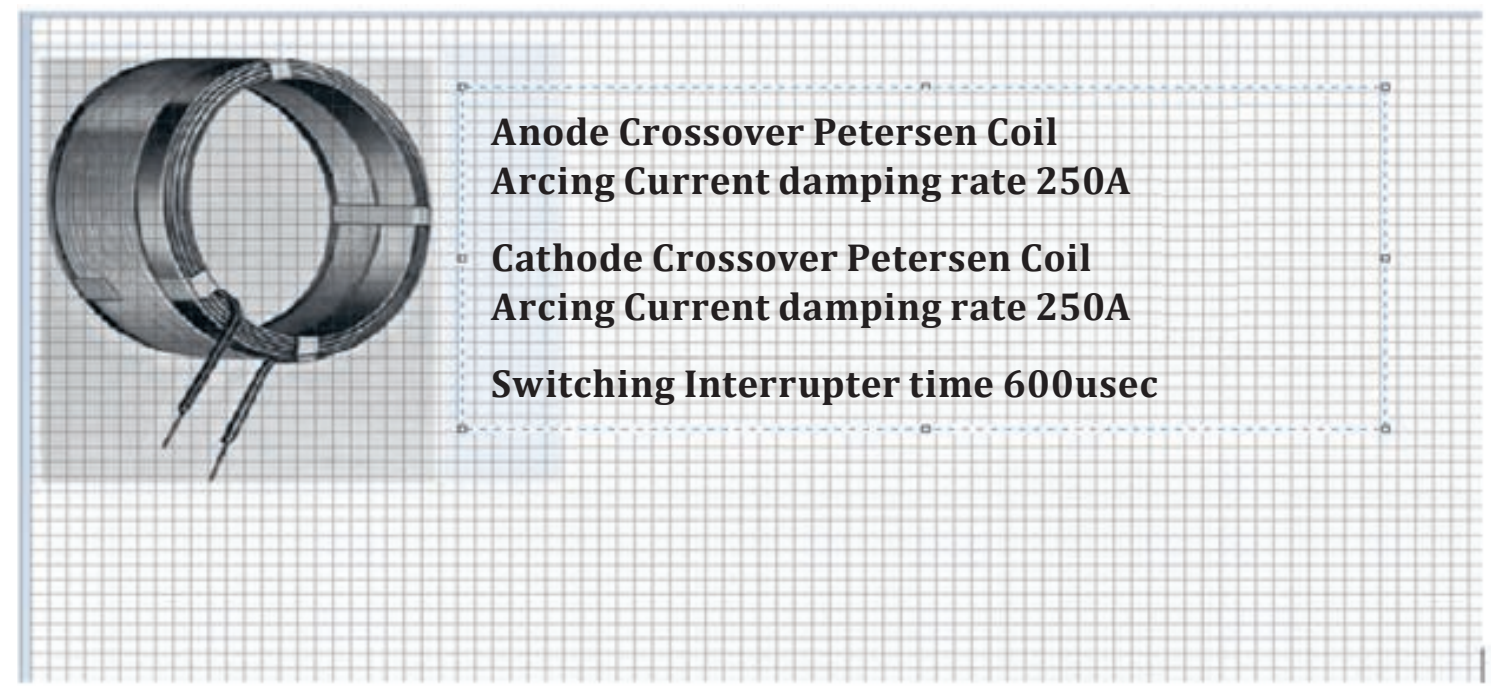

Fig. 1.5. Preliminary designing of fabricated Petersen coil. 


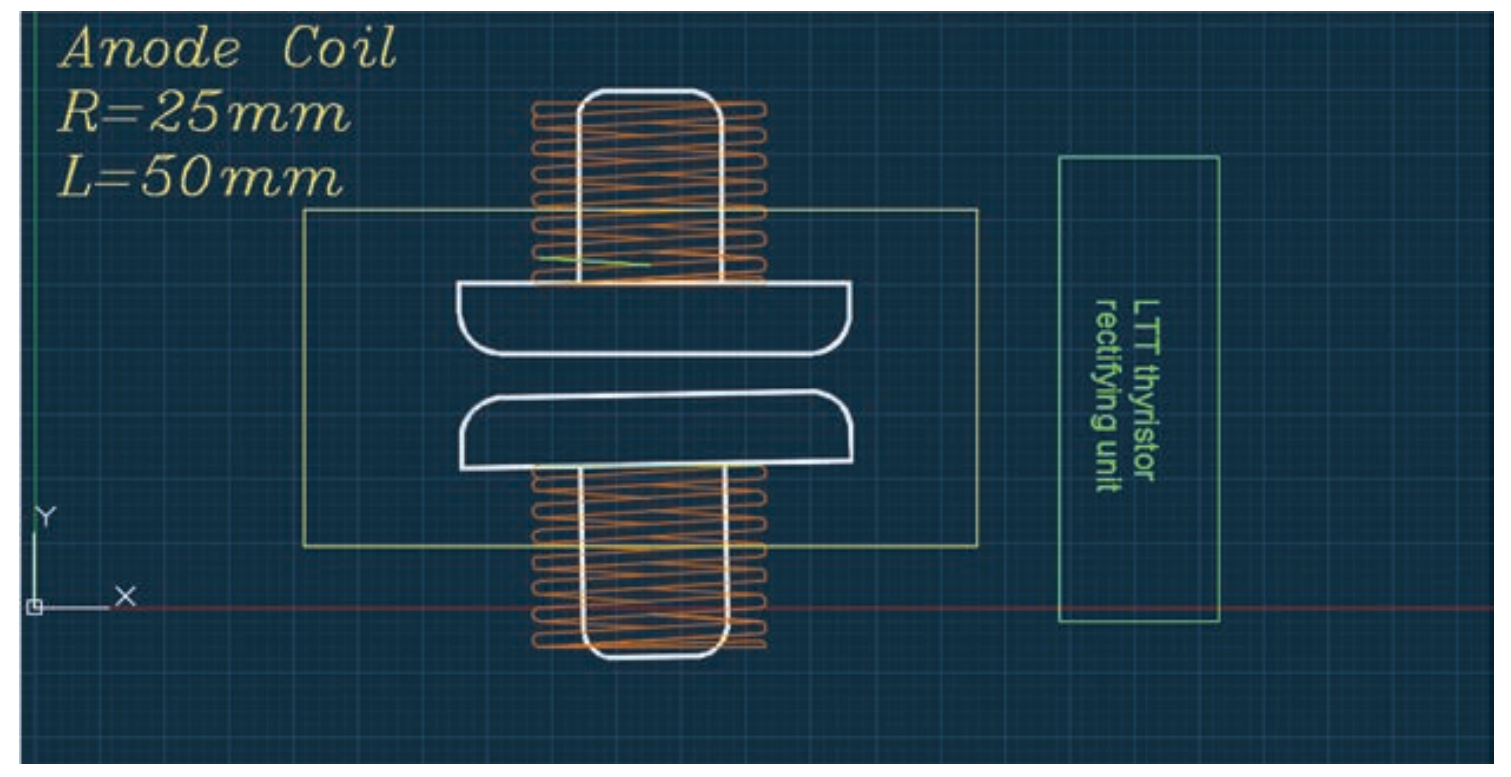

Fig. 1.6. Preliminary designing of fabricated Petersen coil with LTT thyristor (proposed novelty).

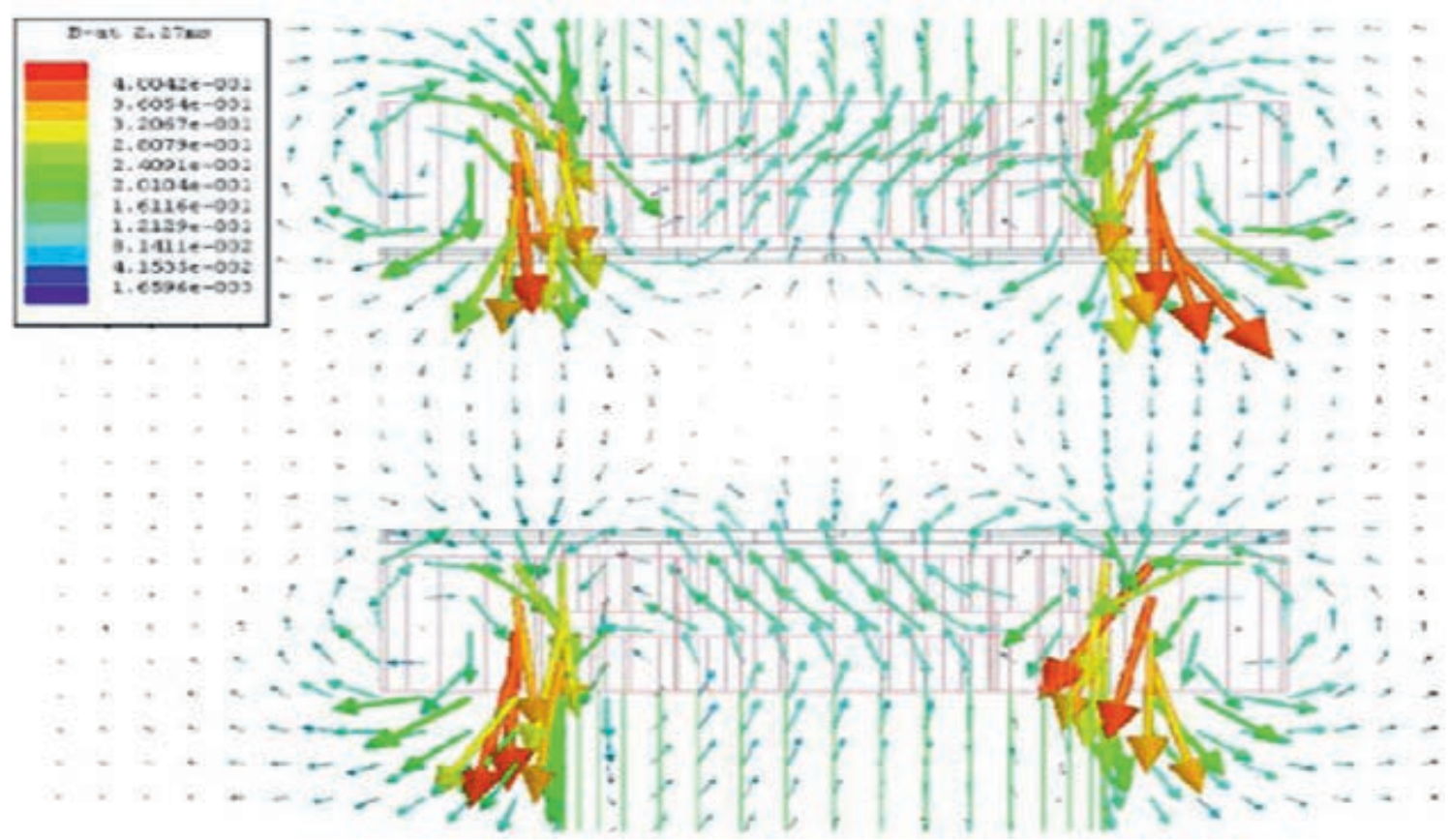

Fig. 1.7. AMF rotates between anode and cathode Petersen coils [27]. 


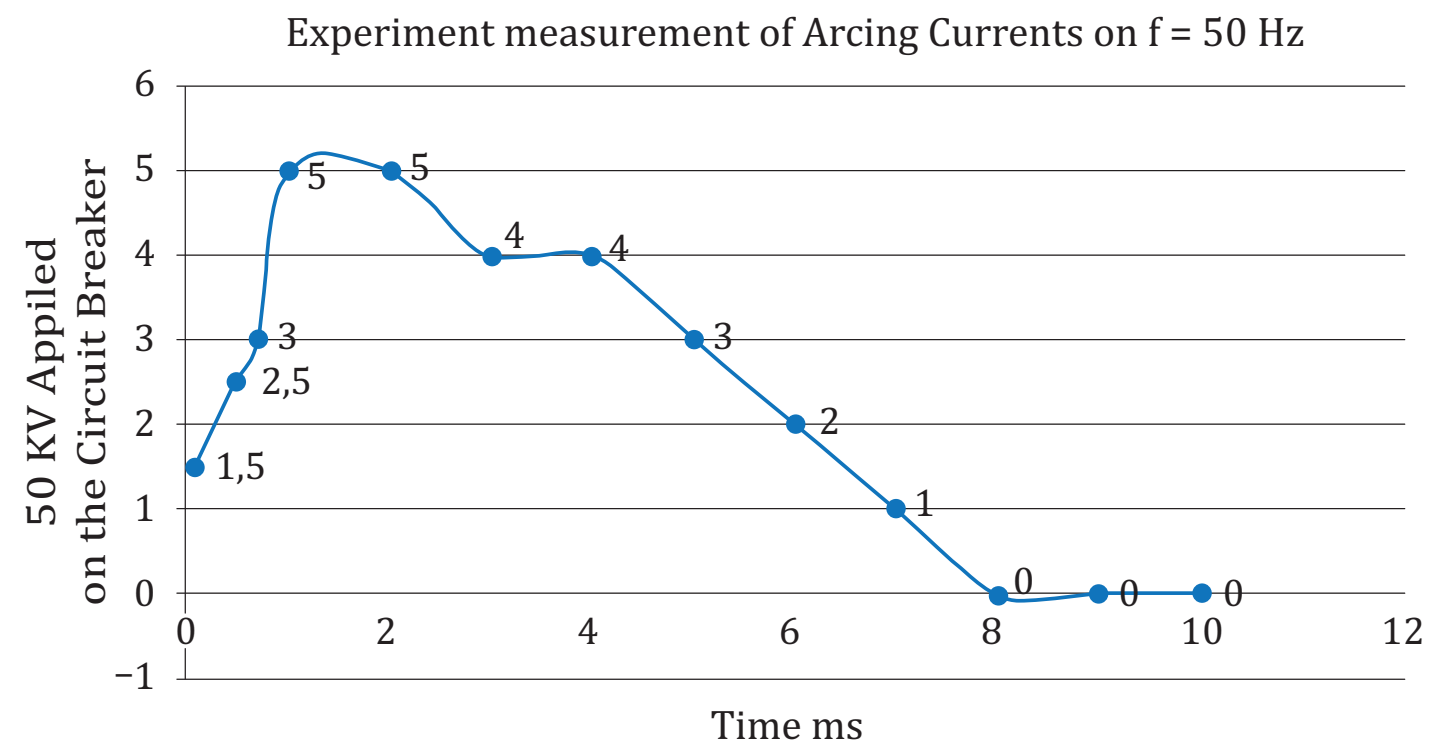

Fig. 1.8. Maximum arcing currents - experiment MATLAB test.
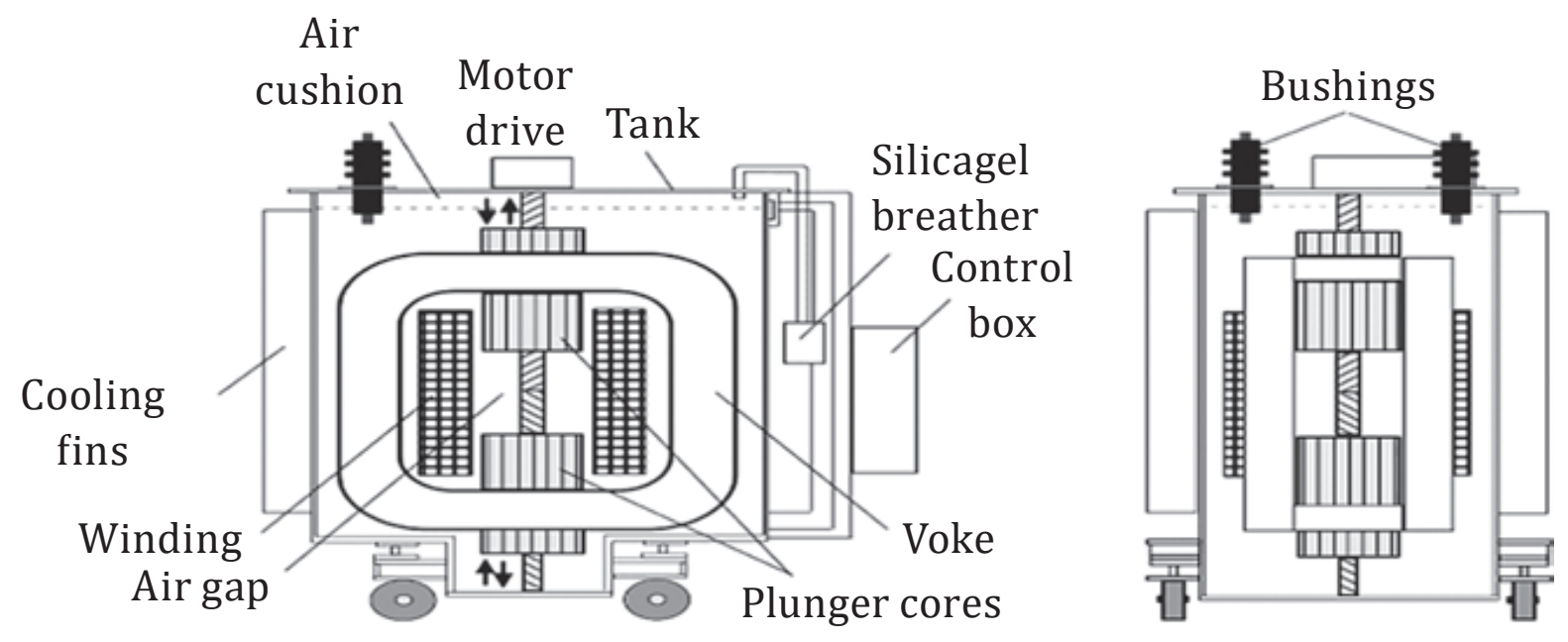

Fig. 1.9. Construction diagram of Petersen reactor coil automatic tuning.

Researching for fabricating of axial magnetic field.

- Quenching of arcing currents.

- Quenching of chopping currents.

- Preventing of initiate transient over voltages.

- Analysis of Petersen two coils - primary windings - secondary windings with moving of secondary coil tap changer automatic tuning principle.

- $U=12 \mathrm{kV}$.

- $I=70 \mathrm{kA}$. 
- $U_{\mathrm{d}}=28 \mathrm{kV}$ Minimum switching impulse.

- $U_{\mathrm{p}}=75 \mathrm{kV}$ Maximum switching impulse.

- Quenching arcing currents - $250 \mathrm{~A}$ at maximum frequency range [50 Hz to $150 \mathrm{~Hz} / 400 \mathrm{~Hz}$ ].

- Maximum time switching of arcing currents [0-600 $\mu \mathrm{s}$.

- Maximum discharging technique of [Coil A - THY - Coil B].

- Insulation level $U_{\mathrm{d}}(\mathrm{kV}$ rms. $1 \mathrm{~min})$ and $U_{\mathrm{p}}(\mathrm{kV}$ peak).

- LTT Thyristors - Lighted Triggered Power Switching [21].

\subsubsection{Mathematical Designing of Petersen Coils}

For designing of Petersen coil automatic tuning for the function of quenching both of arcing currents and chopping currents, it is customary to assume that the highest allowable current is produced at the arc suppression value. Upon this basis the following formula for the ohmic value. The current limiting coil should be considered of a resistor, an inductor, a capacitor or any combination of these.

$$
\begin{aligned}
& I=\frac{1000 S}{U \sqrt{3}}, \\
& Z_{\mathrm{p}}=\frac{\frac{U}{\sqrt{3}}}{C_{\mathrm{o}} \cdot I},
\end{aligned}
$$

where

$\mathrm{Z}_{\mathrm{p}}$ - impedance for anode \& cathode coils, $\Omega$;

$I$ - maximum current passing in coil, amperes, A;

$U$ - transformer turned line volts $12 \mathrm{kV}$;

$S$ - winding of transformer coil, kVA;

$C_{\mathrm{o}}$ - coefficient of arcing currents \& chopping currents.

So, the designing formula for anode and cathode coils is as follows:

$$
\begin{gathered}
Z_{\mathrm{p}}=\frac{U^{2}}{2000 C_{\mathrm{o}} \cdot S} \text { (for single pole of interrupter), } \\
L=\frac{1}{3 \omega c} .
\end{gathered}
$$


Sample 1: $L=16 \mathrm{mH}$ for $Z=32.699 \Omega$ (anode $\&$ cathode coils) $Z_{\mathrm{p}}=32.00 \Omega$ for anode winding coil $-1.1 \mathrm{~mm}$ cross section copper wire.

$Z_{\mathrm{p}}=32.00 \Omega$ for cathode winding coil $-1.1 \mathrm{~mm}$ cross section copper wire.

LTT/THY rating 63 A / $12 \mathrm{kV} \mathrm{/} 1200 \mu$ s/A $180 \mathrm{kA} /$ LTT type.

Dimension of anode $\&$ cathode coils:

- $R=25 \mathrm{~mm}$;

- $L=50 \mathrm{~mm}$.

Pole diameter $=125 \mathrm{~mm}$ standard on the existing vacuum interrupter type SION / 3AES SIMENS $12 \mathrm{kV} / 630 \mathrm{~A}$.

- My novelty confirms that the axial magnetic field shall rotate in the first coil - anode coil.

- For the purpose of process to diverting of three elements outside electroplates.

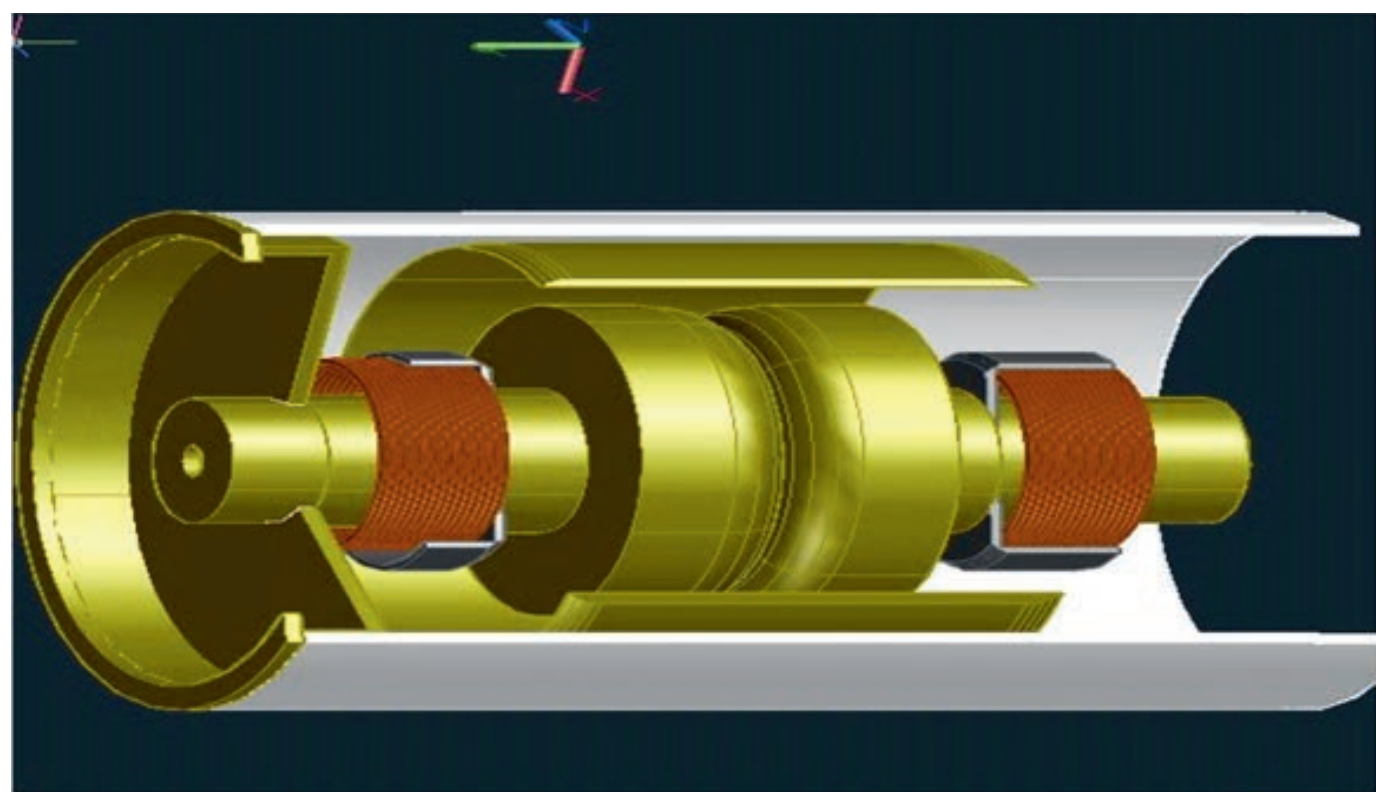

Fig. 1.10. Designing of Petersen reactor coil automatic tuning anode \& cathode. Sample 1. 
Sample 2: $L=\mathbf{2 0} \mathbf{m H}$ for $Z=\mathbf{5 0 . 2 4} \Omega$ (anode $\&$ cathode coils) $Z_{\mathrm{p}}=50 \Omega$ for anode winding coil $-1.55 \mathrm{~mm}$ cross section. $Z_{\mathrm{p}}=50 \Omega$ for cathode winding coil $-1.55 \mathrm{~mm}$ cross section. THY Rating 125 A / 12 kV / 1200 s/A 180 kA / LTT.

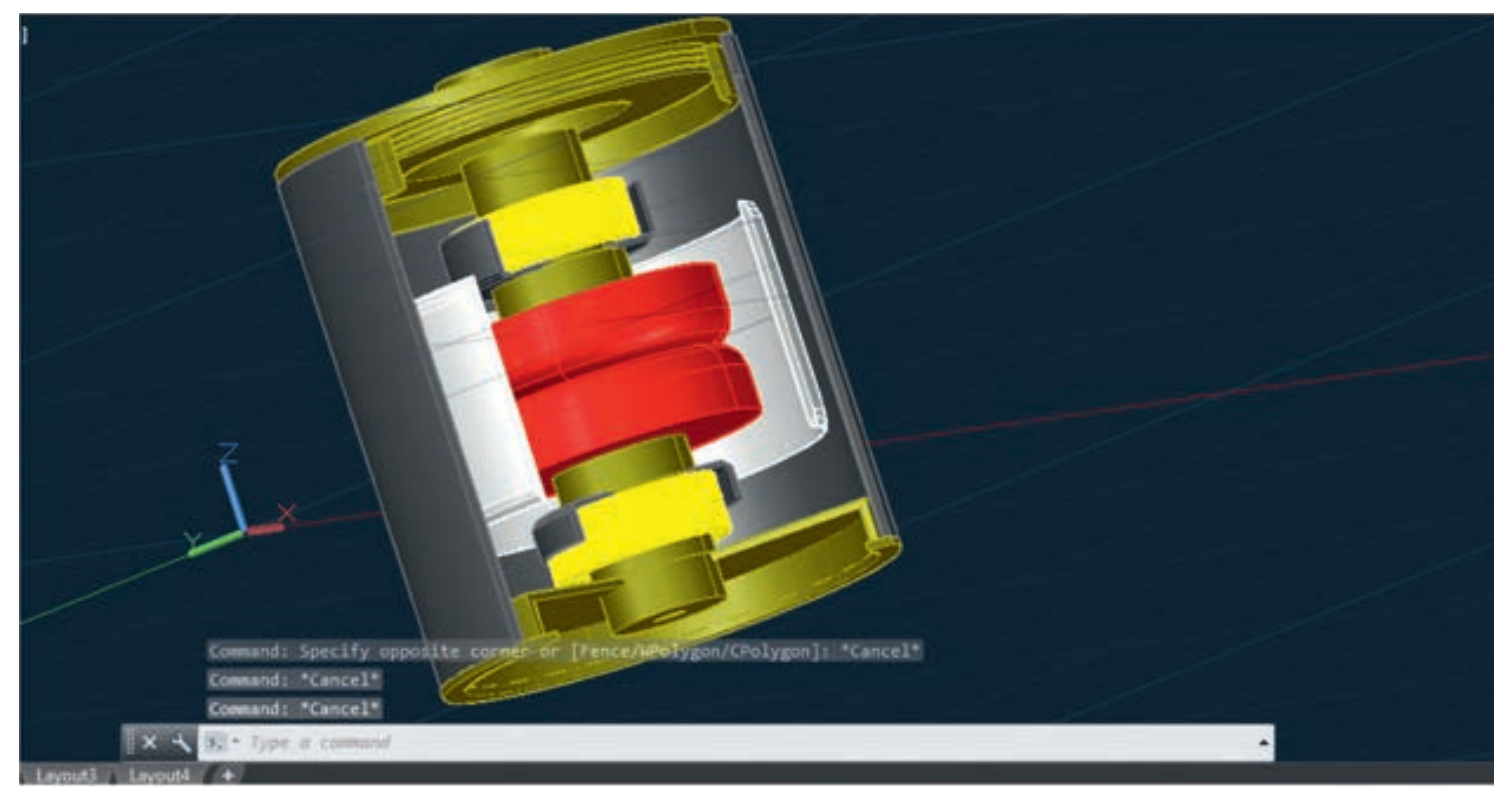

Fig. 1.11. Designing of Petersen reactor coil automatic tuning anode \& cathode. Sample 2.

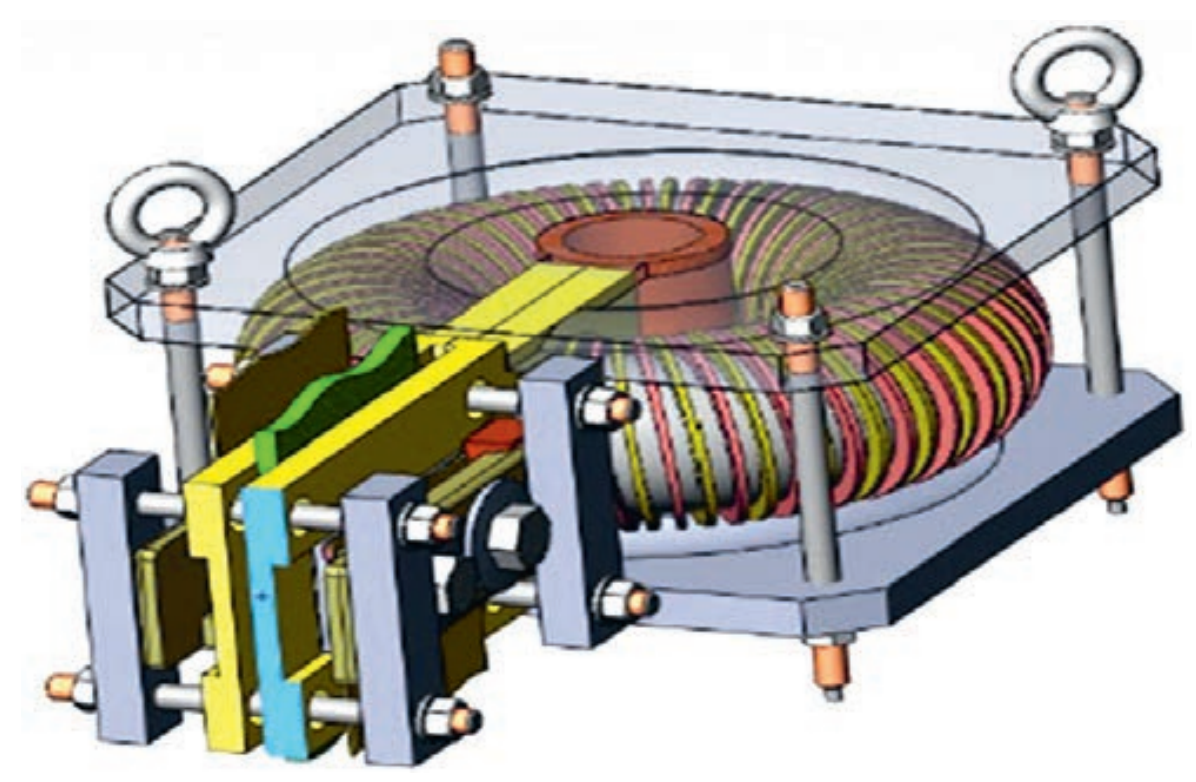

Fig. 1.12. Modification sample of anode \& cathode poles. Sample - St Petersburg Institute. 
- RTU does not have M.V. laboratory

- My analysis for finding similar scientific materials of my novelty.

Sample 3: $L=40 \mathrm{mH}$ for $Z=63.49 \Omega$ (anode $\&$ cathode coils) $Z_{\mathrm{p}}=63 \Omega$ for anode winding coil $-1.75 \mathrm{~mm}$ cross section. $Z_{\mathrm{p}}=63 \Omega$ for cathode winding coil $-1.75 \mathrm{~mm}$ cross section. THY Rating 250 A / 12 kV / $1200 \mu$ s/A 180 kA / LTT.

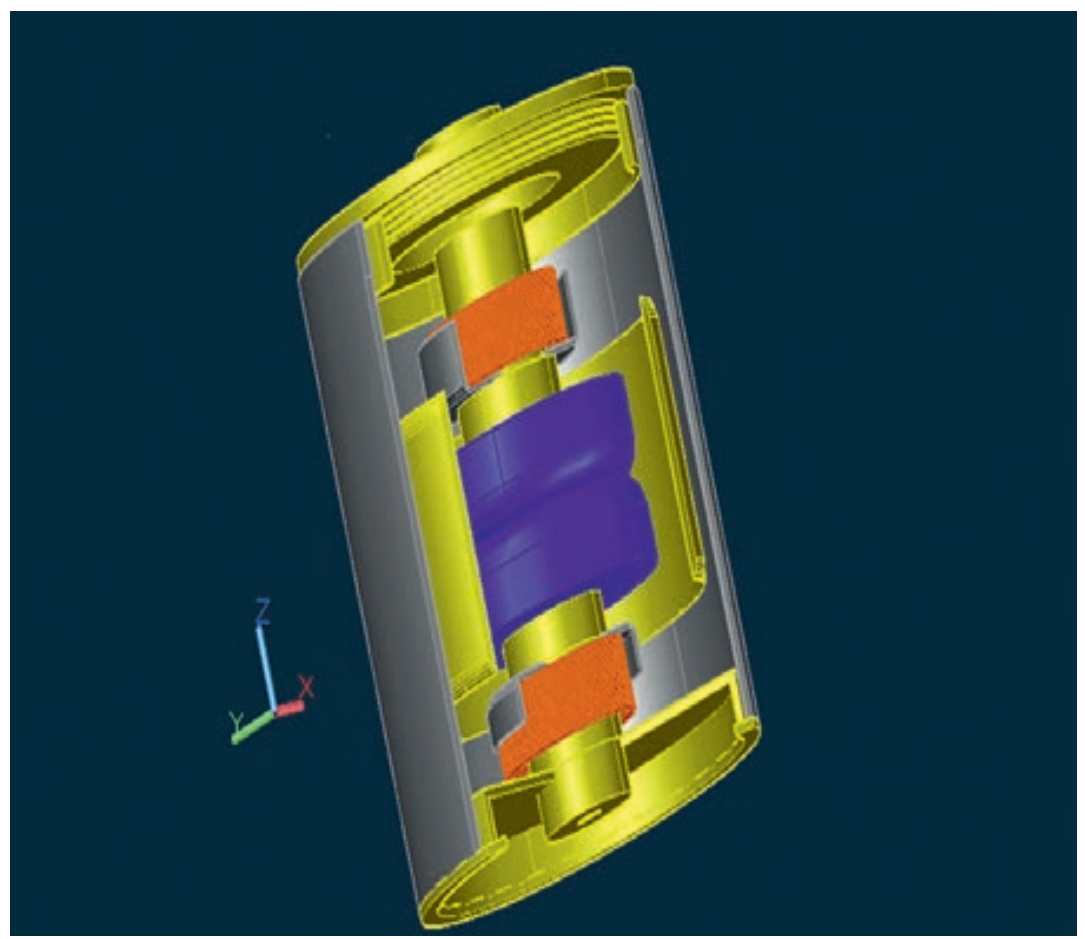

Fig. 1.13. Designing of Petersen reactor coil automatic tuning anode \& cathode. Sample 3. 


\subsection{Inserting of LTT Rectifying Thyristor Setting Circuit}

One concluding theory from a group of Scholars [64]:

$$
\begin{aligned}
I_{0} & =i_{1}+i_{2} . \\
U_{1}+L_{1} \frac{\mathrm{d} i_{1}}{\mathrm{~d} t} & =U_{2}+L_{2} \frac{\mathrm{d} i_{2}}{\mathrm{~d} t} .
\end{aligned}
$$

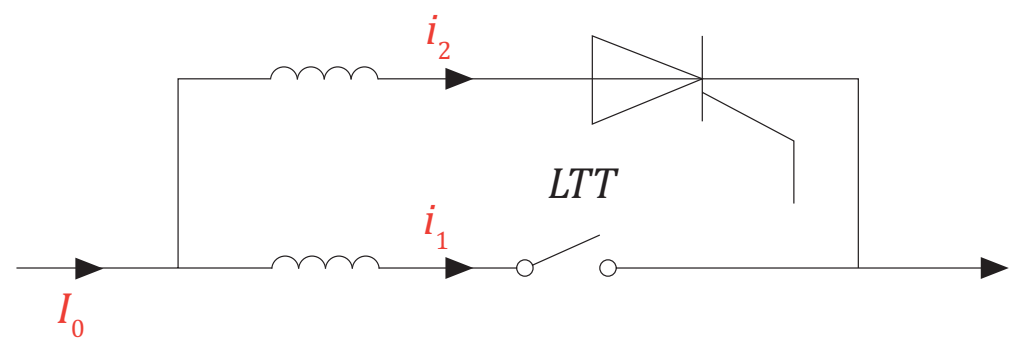

Fig. 1.14. The switching on LTT will be crossing speed by Kirchhoff's law.

\subsection{Optimization of Mathematical Application for Damping Technique}

In order to create mathematical formula, which is being more facility for damping application of two coils (Anode Coil A \& Cathode Coil B) in parallel operation including one thyristor set for soft interrupter, we shall design basic module of inductive reactance value of $20 \mathrm{mH}$ for my Thesis of proposed circuit [11], [21].

\subsubsection{Basic Module of Inductive Reactance Circuit}

$$
\mathrm{e}^{a t} t^{n}=\frac{n !}{(s-a)^{n+1}} \text {. }
$$

Damping real part:

$$
\mathrm{e}^{a t} \cos t(\omega t)=\frac{(s-a)}{(s-a)^{2}+\omega^{2}} .
$$


Damping imaginary part:

$$
\mathrm{e}^{a t} \sin (\omega t)=\frac{\omega}{(s-a)^{2}+\omega^{2}}
$$

In this case of rectifying both of arcing currents and chopping currents $I_{\mathrm{p}}=I_{\mathrm{arc}}+I_{\mathrm{ch}}$.

$$
\begin{gathered}
I_{\mathrm{p}}=\sqrt{\frac{1}{2 \pi} \int_{0}^{\pi} I^{2} \mathrm{~d}(\omega t)=} \\
=\sqrt{\frac{I_{\mathrm{m}}^{2}}{2 \pi}} \int_{0}^{\pi} \sin ^{2}(\omega t) \mathrm{d}(\omega t)=\frac{I_{\mathrm{m}}}{2} .
\end{gathered}
$$

rectifying values of arcing currents and chopping currents

\subsection{Synthesis of Mathematical Model}

1. The main benefit of the fabricated Petersen coil is that the axial magnetic field will be rotated as radial magnetic field when passing the sealing vacuum tube in each pole. This phenomenon is very important that arcing currents will not growth escalation from the rate of arc suppression coil. This my application technique was verified by the research manuscript [5].

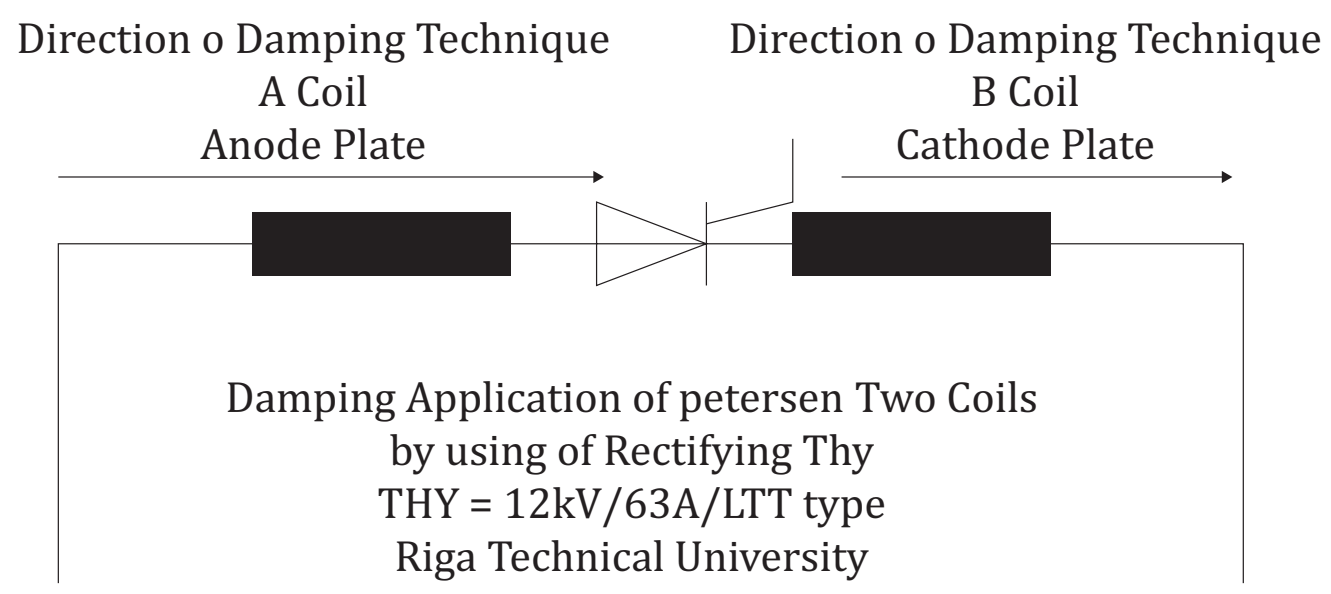

Fig. 1.15. Mathematical model - basic module circuit for rectifying application (novelty). 
2. The designing of winding coils was verifying the equation (1.1) for calculating of the maximum both of arcing currents and chopping currents.

3. LTT Thyristor were chosen from the data sheets specification [95].

\subsection{Synthesis of MATLAB/Simulink Models}

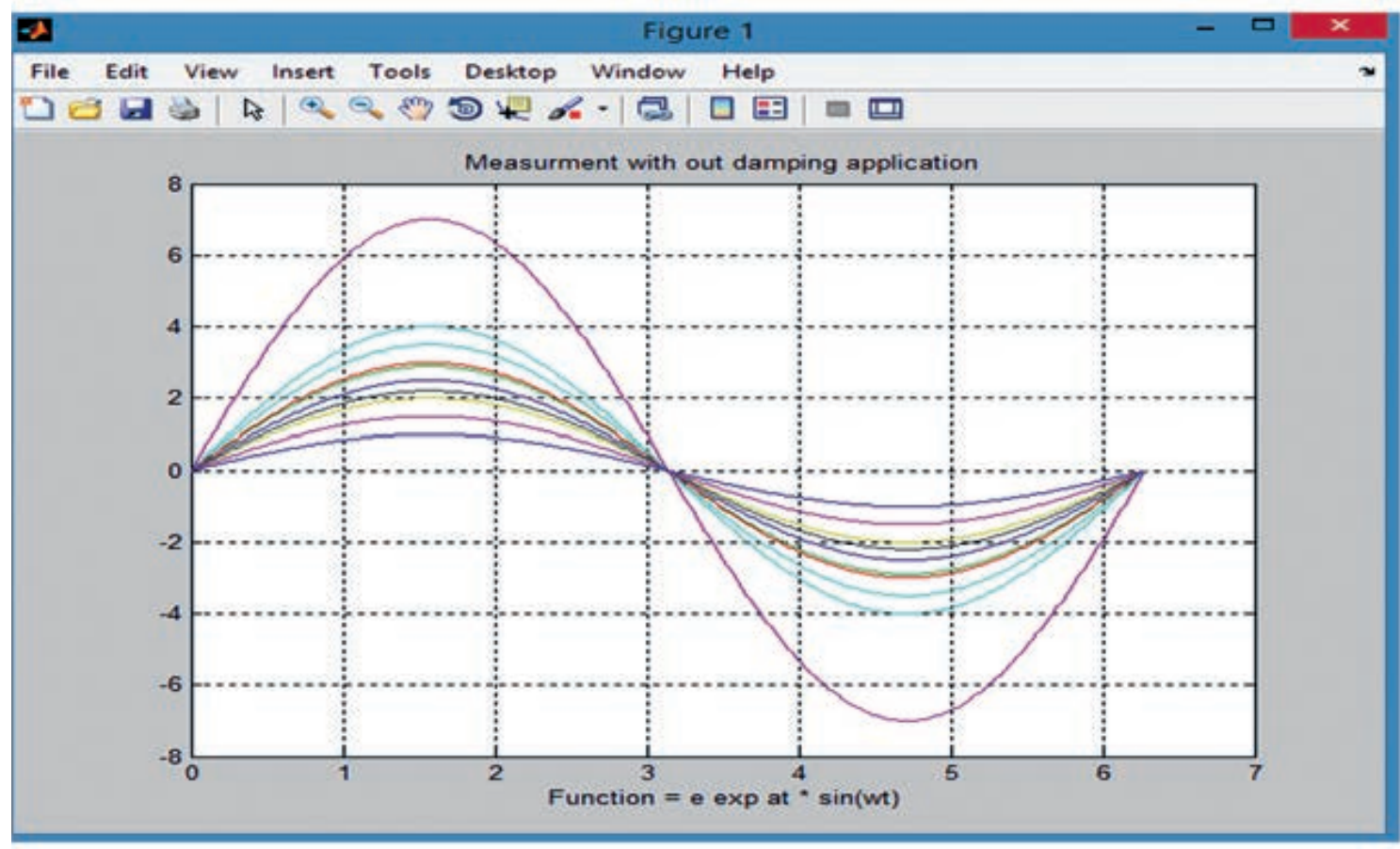

Fig. 1.16. Basic module circuit without damping application - MATLAB.

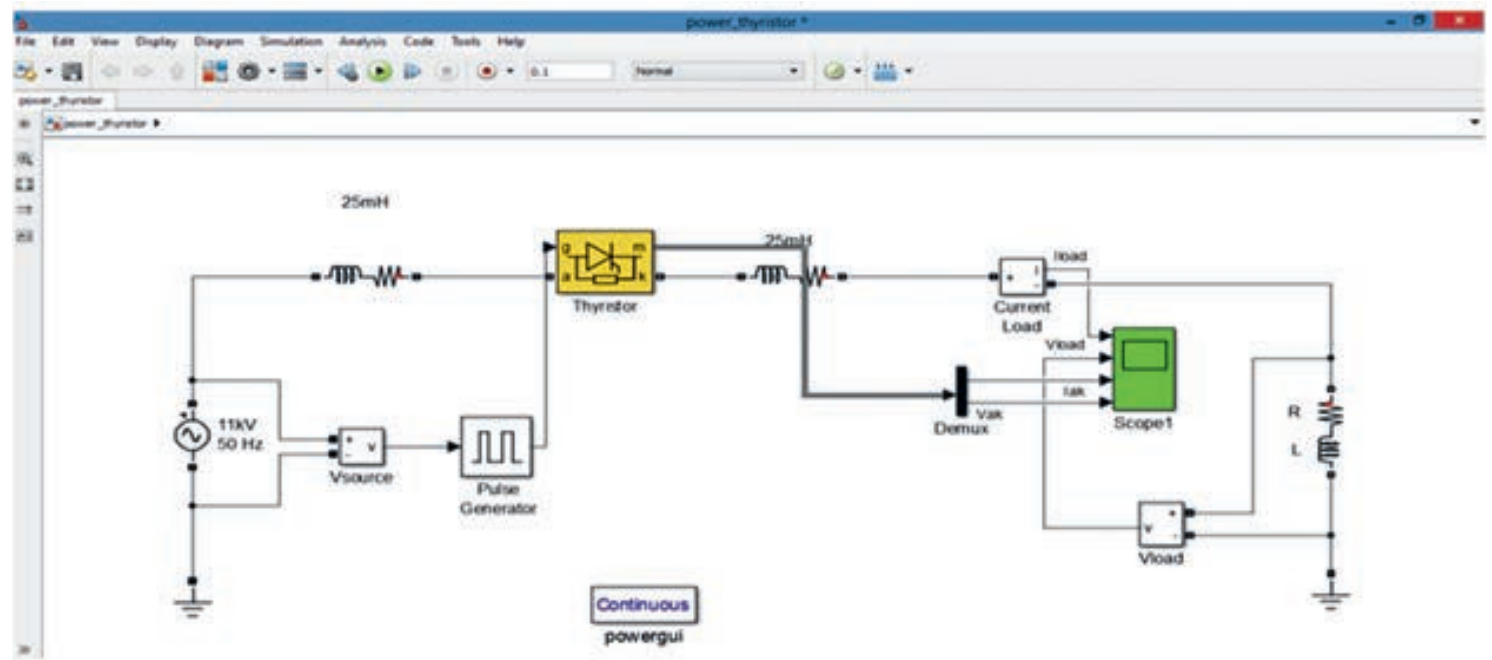

Fig. 1.17. MATLAB/Simulink Basic Module. 


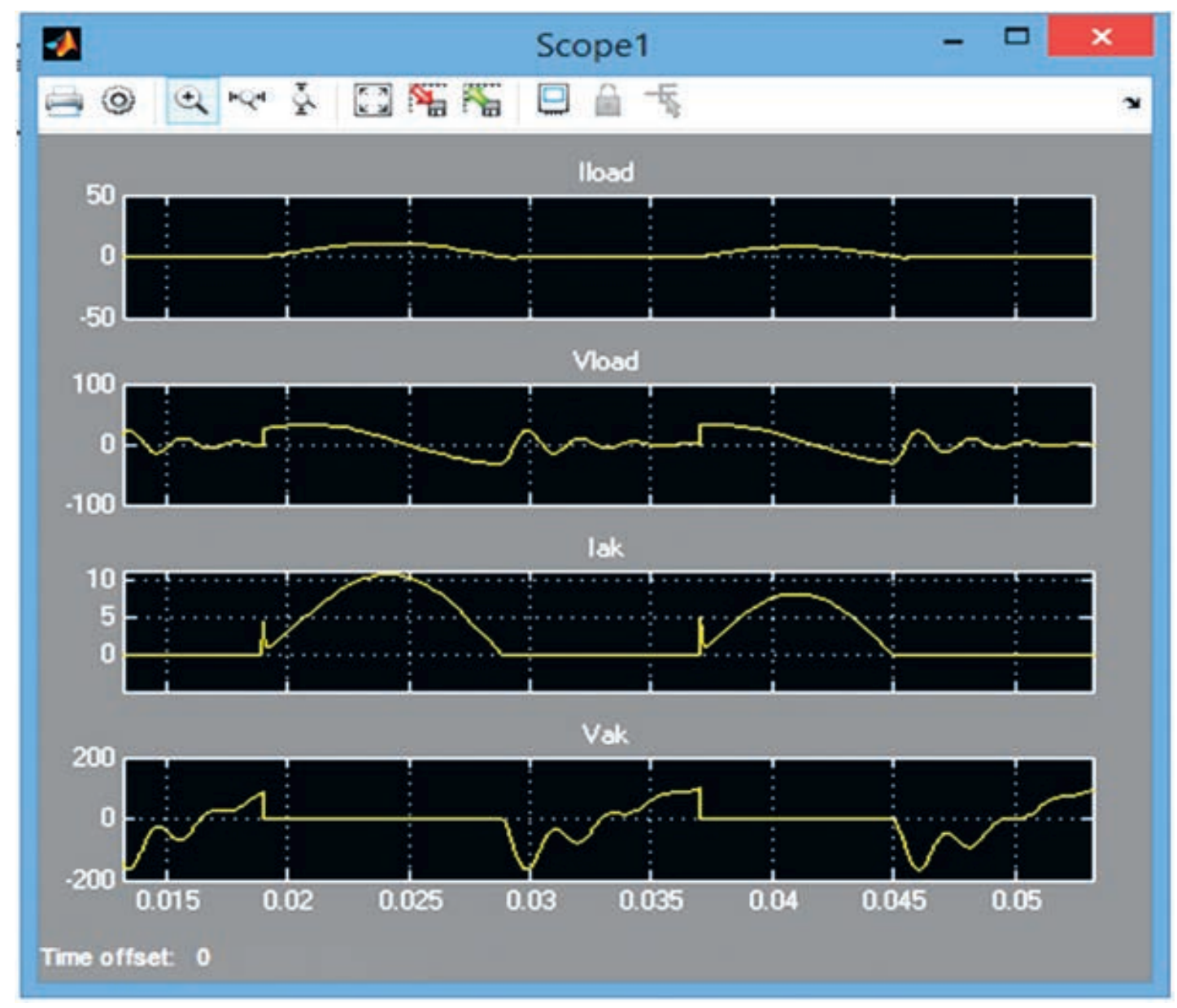

Fig. 1.18. MATLAB/Simulink Basic current.

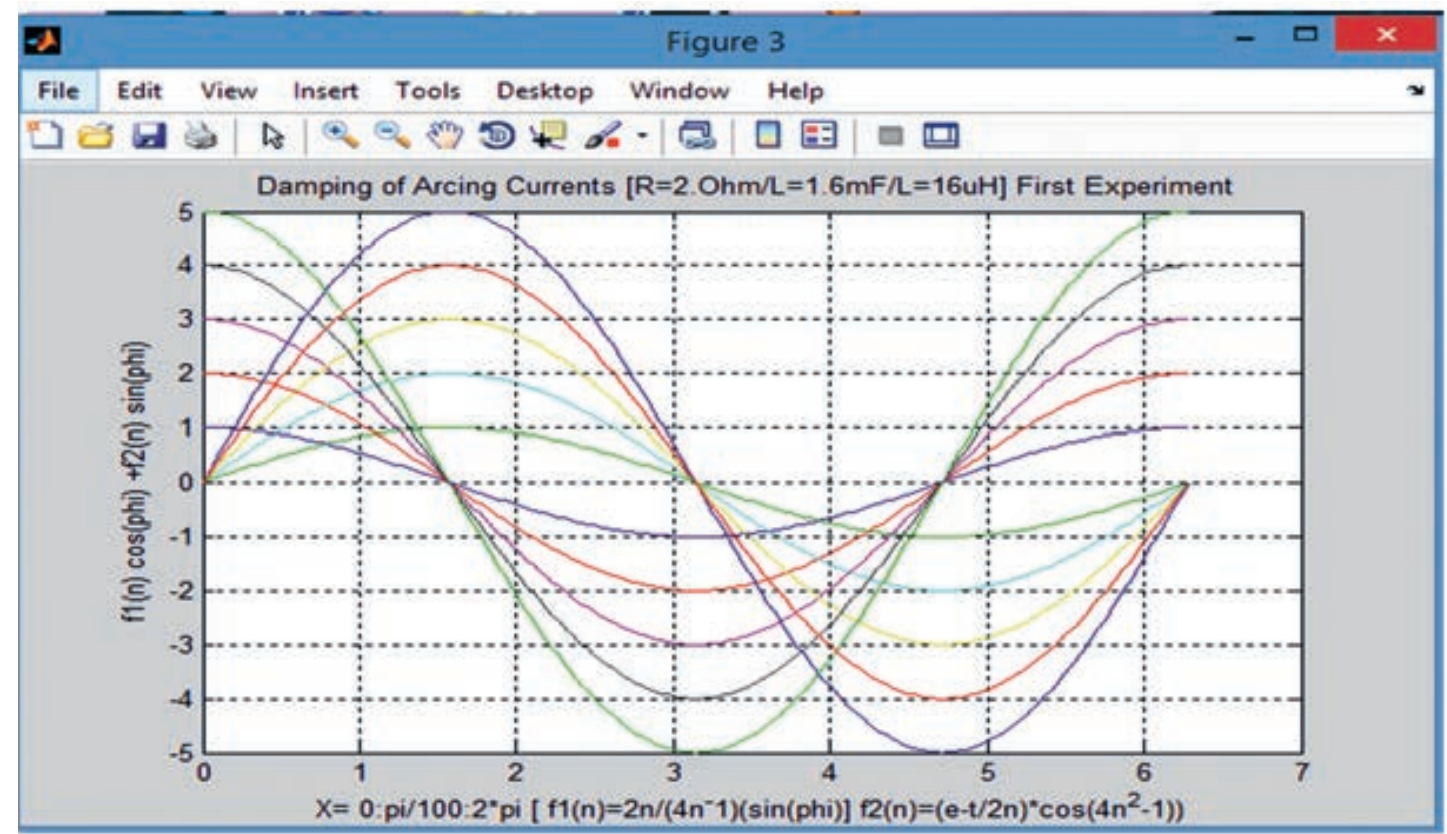

Fig. 1.19. Generalized plot of Laplace transformation - damping circuit - MATLAB. 


\subsection{Conclusions}

Allan Greenwoods and his colleagues were creating a mathematical method for created damping general formula. My development that was made some experiment tests by using MATLAB/Simulink for clarifying the benefit of the mathematical application damping rectifying technique [6], [11], [12].

$$
i_{L(s)}=\frac{U_{(0)}}{L} \cdot \frac{1}{\left(S^{2}+\frac{S}{T P}+\frac{1}{T^{2}}\right)},
$$

whereas

$$
L C=T^{2} .
$$

Mathematical parameters for theory of damping circuits:

$$
\begin{gathered}
\frac{U_{\text {out }}}{U_{\text {in }}}=\frac{1}{L S^{2}+R S+1}, \\
\frac{C_{(s)}}{R_{(s)}}=\frac{1}{\left(S^{2}+2 \xi s+1\right)} .
\end{gathered}
$$

To determine the first overshoot at $T_{\max }$

$$
T_{\max }=\frac{n \pi}{\omega_{n} \sqrt{\left(1-\zeta^{2}\right)}} .
$$

In order to generate calculating parameters for designing $(L)$ reactor which is able to damping all transient over voltages, there are three requirements that need to be considered, precisely $f_{1}, f_{2}$ and $f_{3}$.

$$
f=\frac{1}{2 \pi \sqrt{L C}}
$$




\section{MATHEMATICAL PARAMETERS}

\subsection{Experiment Test for Calculating of Oscillating - Chopping Currents - Proving Method}

Calculating of the first peak value of chopping currents and evaluate the transient over voltages on Petersen Coil Reactor Transformer was verified on one reactor coil with ABB laboratory in Drammen, Norway [10].

$$
\begin{gathered}
Z_{\text {Load }}=3000 \Omega, \\
U_{\mathrm{T}}=I_{\text {ch }} Z_{\text {Load }},
\end{gathered}
$$

where

$U_{\mathrm{T}}$ - voltage of the first peak value;

$I_{\text {ch }}$ - current chopping;

$Z_{\text {Load }}$ - load impedance.

In order to verify the statistical approach of the correctly calculation of first peak values for each circuit breaker $U_{\mathrm{T}}=0.9$. $3000=2700 \mathrm{~V}$ first peak transient voltage.

$U_{\text {MAX }}=2.7 \mathrm{kV}+10 \mathrm{kV}=12.7 \mathrm{kV}$ reasonable transient over-voltage. Thus the table indicates the data sheet regarding my calculation permissible for full operation loads.

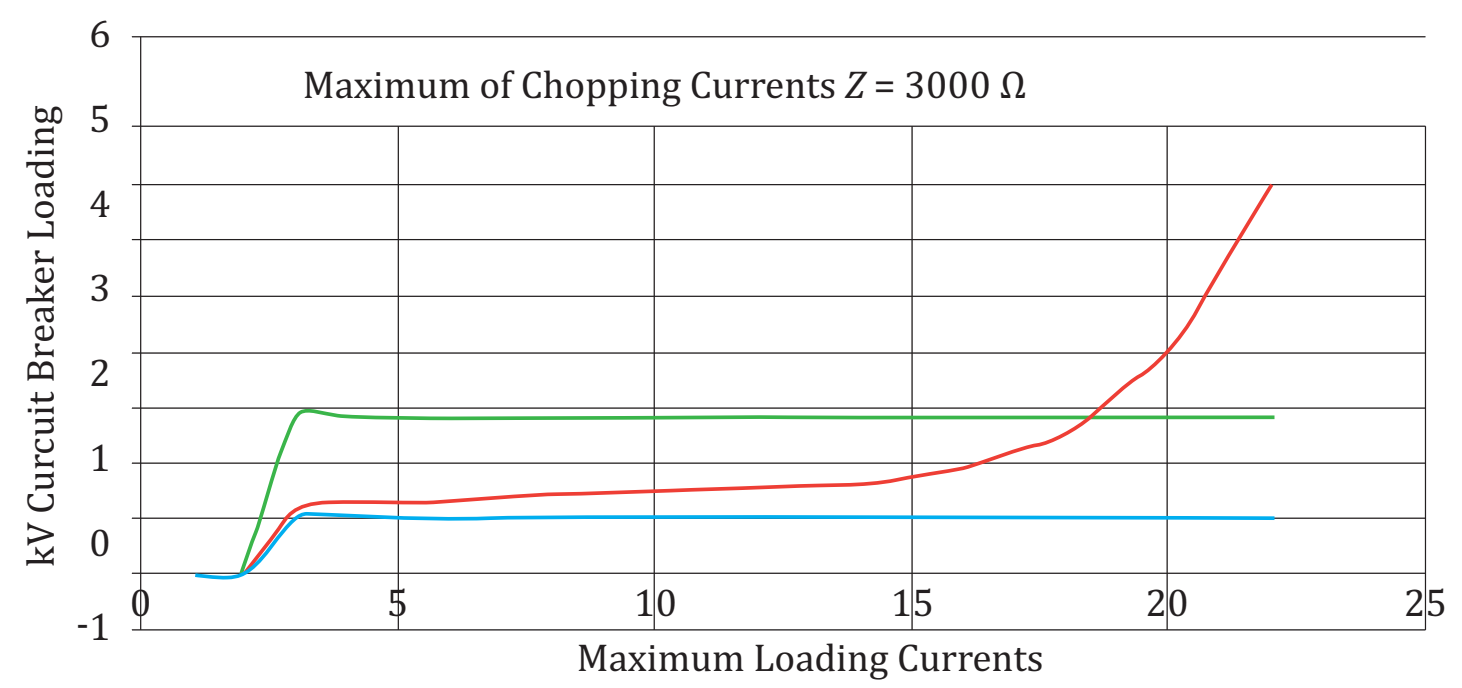

Fig. 2.1. Data sheet for finding maximum chopping currents. 
Table 2.1

Calculating Chopping Currents and Transient Over Voltages $-Z=3000 \Omega$

\begin{tabular}{|c|c|c|c|c|c|c|}
\hline No & $\boldsymbol{I}_{\mathbf{}^{\prime}} \mathbf{A}$ & $\boldsymbol{U}_{\mathbf{T}^{\prime}} \mathbf{k V}$ & $\boldsymbol{U}, \mathbf{k V}$ & $\boldsymbol{U}_{\text {max }^{\prime}} \mathbf{k V}$ & $\boldsymbol{U}_{\mathbf{d}^{\prime}} \mathbf{k V}$ & Results \\
\hline 1 & 0.1 & 0.3 & 10 & 10.3 & 28 & Acceptable \\
\hline 2 & 0.2 & 0.6 & 10 & 10.6 & 28 & Acceptable \\
\hline 3 & 0.3 & 0.9 & 10 & 10.9 & 28 & Acceptable \\
\hline 4 & 0.5 & 1.5 & 10 & 11.5 & 28 & Acceptable \\
\hline 5 & 0.9 & 1.7 & 10 & 12.7 & 28 & Acceptable \\
\hline 6 & 1 & 3 & 10 & 13 & 28 & Acceptable \\
\hline 7 & 2 & 6 & 10 & 16 & 28 & Acceptable \\
\hline 8 & 3 & 9 & 10 & 19 & 28 & Acceptable \\
\hline 9 & 4 & 12 & 10 & 22 & 28 & Acceptable \\
\hline 10 & 5 & 15 & 10 & 25 & 28 & Critical \\
\hline 11 & 6 & 18 & 10 & 28 & 28 & Critical \\
\hline 12 & 7 & 21 & 10 & 31 & 28 & Disruptive \\
\hline 13 & 8 & 24 & 10 & 34 & 28 & Disruptive \\
\hline 14 & 9 & 27 & 10 & 37 & 28 & Disruptive \\
\hline 15 & 10 & 30 & 10 & 40 & 28 & Disruptive \\
\hline
\end{tabular}




\subsection{Experiment Prototype for Magnetic Field Behavior - Fabricated Process}

Table 2.2

Experiment Indicates the Fixed Arcing Currents Value

\begin{tabular}{|c|c|c|c|c|}
\hline Number & Time ms & $\begin{array}{c}\text { Arcing Voltage } \\
\text { KV }\end{array}$ & $\begin{array}{c}\text { Peak Value } \\
\text { KA }\end{array}$ & Results \\
\hline 1 & 0 & 0 & 0 & $i=I_{\mathrm{m}} \sin \omega t$ \\
\hline 2 & 1,5 & 10 & 13,7 & Pārsniegts \\
\hline 3 & 1,9 & 20 & 15,5 & Pārsniegts \\
\hline 4 & 2,0 & 25 & 17,0 & Pārsniegts \\
\hline 5 & 2,0 & 30 & 14,1 & Stabils \\
\hline 6 & 2,5 & 35 & 14,0 & Stabils \\
\hline 7 & 3,0 & 40 & 13,0 & Samazināts \\
\hline 8 & 3,0 & 45 & 12,0 & Samazināts \\
\hline 9 & 3,5 & 50 & 12,0 & Stabils \\
\hline 10 & 3,5 & 55 & 12,0 & Stabils \\
\hline 11 & 4,0 & 60 & 12,0 & Stabils \\
\hline
\end{tabular}

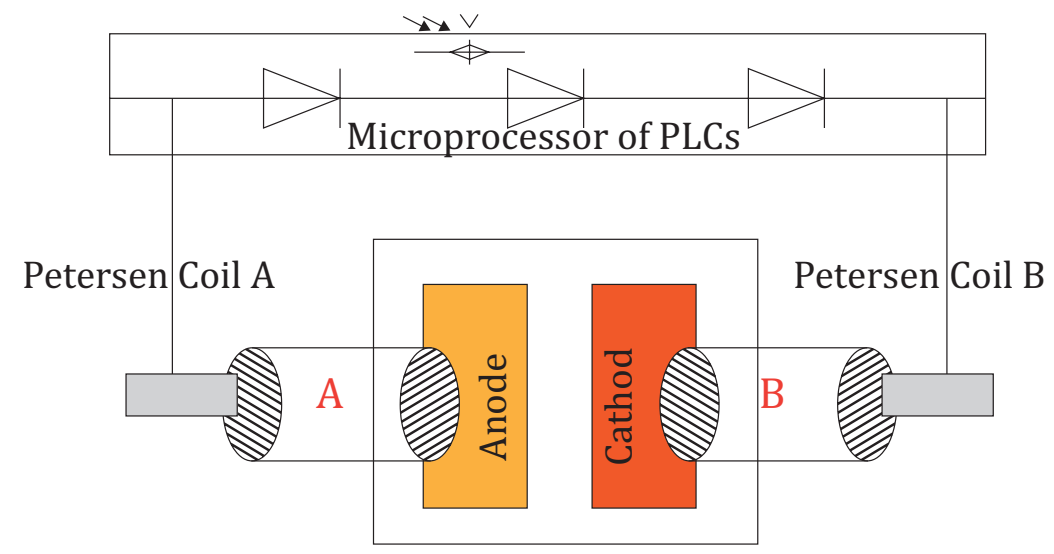

Prelimenary designing of two coils for soft starter

$11 \mathrm{kV} / 250 \mathrm{~A} / 600 \mu \mathrm{s} / 25 \mathrm{mH}$

Vacuum Interrupter auxiliary circuit

Fig. 2.2. Preliminary designing of soft starter unit (novelty). 


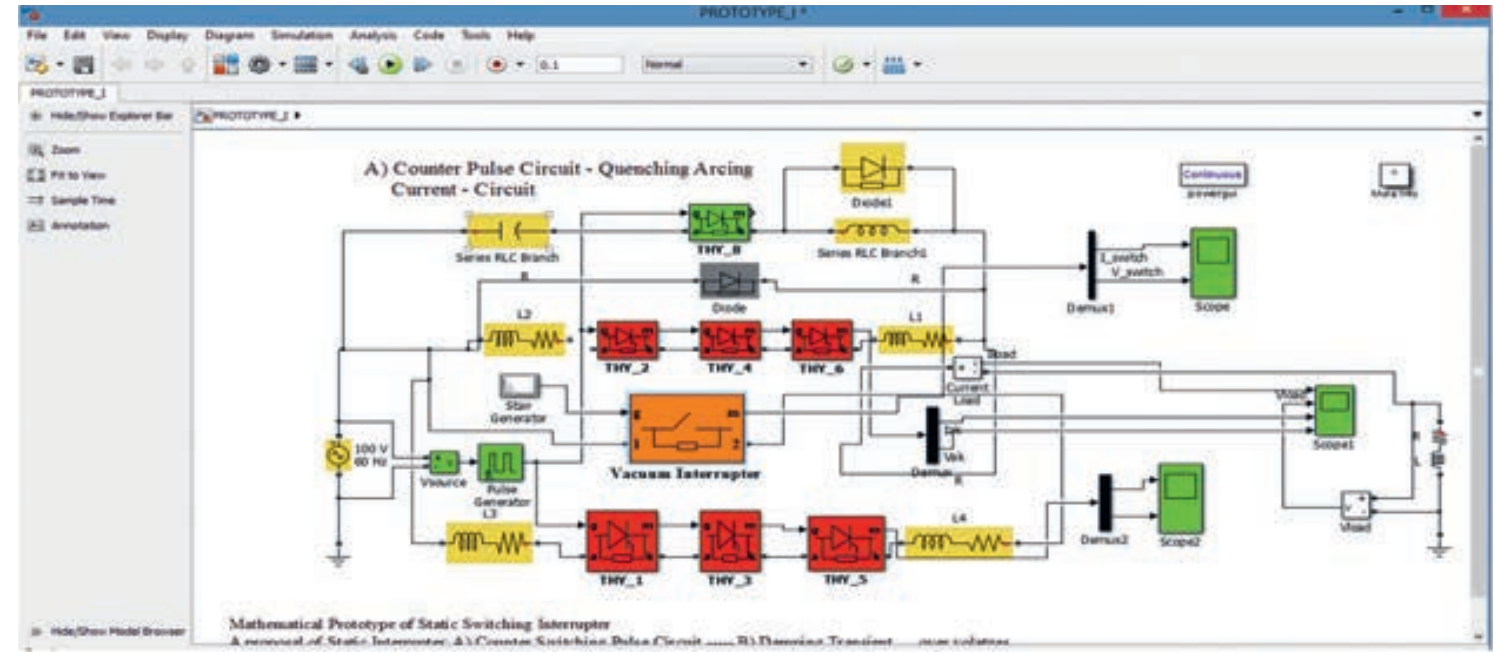

Fig. 2.3. MATLAB/Simulink - soft starter unit of vacuum interrupter.

\section{MAIN CONCLUSIONS}

1. The author proposes an automatic adjustment of Petersen reactor coils: the dual-winding coils have improved damping of both the arc current and the chopping current with a soft switching circuit breaker, which offers a switching pulse correction process.

2. The MATLAB method proposed by the author provides optimized calculation of the corrective LTT switching for a $12 \mathrm{kV} / 63 \mathrm{~A} /$ $3 \mathrm{~A}$ set of $12 \mathrm{kV} / 125 \mathrm{~A} / 5 \mathrm{~A}$ and $12 \mathrm{kV} / 250 \mathrm{~A} / 7 \mathrm{~A}$.

3. The developed process that describes the sequential modeling process for a softswitching of circuit breaker.

4. The result of the author's development is a switching process of up to $600 \mu \mathrm{s}$.

5. The author concludes that static discharge switching times do not affect the switching process.

6. The author proposes the use of softswitching circuit breakers with two Petersen coils as a new technology in medium voltage networks. 


\section{BIBLIOGRAPHY}

[1] X. Yao, Z. Xiangjun, L. Zhanglei, and Y. Wentao, „Novel Control Techniques of Petersen-Coil” 2008 IEEE International Conference on Industrial Technology, Apr. 2008.

https://doi.org/10.1109/icit.2008.4608390

[2] G. R. Mitchell „The High Current Vacuum Arcs and Its Relevance to Circuit Interrupter," PhD thesis, London University Polytechnic.

[3] L. P. Harris, „A Mathematical Model for Cathode Spot Operation” 13th international symposium on Discharges and electrical insulation in Vacuum, Albuquerque, NM, USA.

[4] M. Braunovic, N. K. Myshkin, and V. V. Konchits, Electrical Contacts, Fundamentals, Applications and Technology. CRC Press, 2006.

[5] S. Cheng and J. Wang, „Study on High-Current Vacuum Arc Characteristics Under Self-Generated Axial Magnetic Field of Contact at a Long Contact Gap for High-Voltage Vacuum Interrupters," IEEE Transactions on Plasma Science, vol. 37, no. 1, pp. 243-253, Jan. 2009. https://doi.org/10.1109/tps.2008.2001776

[6] E. Kreyszig, „Laplace Transform Theory and Applications,” in Advance Engineering Mathematics, pp. 192-234.

[7] W. Merz and M. Grimes, „Fast opening Switch Approach for High-Voltage Vacuum Tube Protection Application," 2012 IEEE International Power Modulator and High Voltage Conference (IPMHVC), Jun. 2012. https://doi.org/10.1109/ipmhvc.2012.6518741

[8] B. Fridman, R. Enikeev, N. Kovrizhnykh, A. Pekhotnyi, A. Roshal, R. Serebrov, and K. Kharcheva, "Capacitor bank for Fast Discharge Unit of iter facility," 2011 IEEE Pulsed Power Conference, Jun. 2011. https://doi.org/10.1109/ppc.2011.6191678

[9] R. A. Serebrov, B. E. Fridman, A. A. Khapugin, and V. A. Martynenko, „Development and Research of Heavy Pulse Current LTT Switches," IEEE Transactions on Plasma Science, vol. 44, no. 7, pp. 1195-1201, Jul. 2016. https://doi.org/10.1109/tps.2016.2580004

[10] S. J. Gatan, „Synchronizing Switching Times of Vacuum Interrupters for Medium Voltage Switchboards' Techniques", 2016 Third International Conference on Artificial Intelligence and Pattern Recognition (AIPR), Sep. 2006. https://doi.org/10.1109/icaipr.2016.7585204

[11] A. Greenwood and T. Lee, „Generalized Damping Curves and Their Use in Solving Power-Switching Transients," IEEE Transactions on Power Apparatus and Systems, vol. 82, no. 67, pp. 527-535, Aug. 1963.

https://doi.org/10.1109/tpas.1963.291445 
[12] C. Peng, A. Q. Huang, and X. Song, „Current Commutation in a Medium Voltage Hybrid DC Circuit Breaker Using $15 \mathrm{kV}$ Vacuum Switch and SiC Devices," 2015 IEEE Applied Power Electronics Conference and Exposition (APEC), Mar. 2015. https://doi.org/10.1109/apec.2015.7104661

[13] MATLAB/SIMULINK software application experiment tests.

[14] J. F. Perkins, „Evaluation of Switching Surge Overvoltages on Medium Voltage Power Systems," IEEE Transactions on Power Apparatus and Systems, vol. PAS-101, no. 6, pp. 1727-1734, Jun. 1982. https://doi.org/10.1109/tpas.1982.317226

[15] High Power Directed - light -Triggered Thyristor valve Technology. The basis for advanced power electronics, solutions in transmission systems - H. V laboratory testing and construction research institute SIEMENS PTD-H 17V/Lips/05-04/2002.

[16] S. J. Gatan, „Algorithmic Application for Calculation of Chopping Currents and High Transient Over-Voltages for a New Vacuum Interrupter," 2017 International Scientific Conference on Information, Communication and Energy Systems and Technologies (ICEST 2017). ISSN 2603-3259.

[17] R. P. P. Smeets, D. W. Thielens, and R. W. P. Kerkenaar, „The Duration of Arcing Following Late Breakdown in Vacuum Circuit Breakers," IEEE Transactions on Plasma Science, vol. 33, no. 5, pp. 1582-1588, Oct. 2005. https://doi.org/10.1109/tps.2005.856503

[18] Z. Liying, Q. Ming, W. Jianwen, and C. Bo, „Splitting of Vacuum Arc Column in Transverse Magnetic Field Contacts at Intermediate-Frequency," 2015 3rd International Conference on Electric Power Equipment - Switching Technology (ICEPE-ST), Oct. 2015. https://doi.org/10.1109/icepe-st.2015.7368366

[19] H. J. Boenig, J. W. Schwartzenberg, L. J. Willinger, D. E. Piccone, D. A. Lopez, and H. A. Smolleck, „Design and Testing of High Power, Repetitively Pulsed, Solid-State Closing Switches," IAS '97. Conference Record of the 1997 IEEE Industry Applications Conference Thirty-Second IAS Annual Meeting. https://doi.org/10.1109/ias.1997.628986

[20] S. Cheng, S. Xiu, Z. Liu, and J. Wang, „Study on a New Single Coil-Type Axial Magnetic Field Contact for High-Voltage Vacuum Interrupters," IEEE Transactions on Plasma Science, vol. 35, no. 2, pp. 425-433, Apr. 2007. https://doi.org/10.1109/tps.2007.893264

[21] Siemens-Sustainable Energy. http://www.energy.siemens.com.

[22] [Online]. Available: http://www.amsc.com. [Online]. Available: http:// www.superpower-inc.com. 
[23] S. Pamidi, J. Kvitkovic, U. Trociewitz, S. Ishmael, R. Meinke, and G. Stelzer, „A Novel Magnet for AC Loss Measurements on 2G Superconductor Rings and Coils in Axial and Radial Magnetic Fields," IEEE Transactions on Applied Superconductivity, vol. 22, no. 3, pp. 9003004-9003004, Jun. 2012.

https://doi.org/10.1109/tasc.2011.2176460 
